UNIVERSITY OF GOTHENBURG

SCHOOL OF BUSINESS, ECONOMICS AND LAW

WORKING PAPERS IN ECONOMICS

No 543

\title{
From Boom to Bust and Back Again: \\ A dynamic analysis of IT
}

\author{
Florin G. Maican
}

September 2012

ISSN 1403-2473 (print)

ISSN 1403-2465 (online) 


\title{
From Boom to Bust and Back Again: A Dynamic Analysis of IT Services*
}

\author{
Florin Maican ${ }^{\dagger}$
}

Draft: September 12, 2012

\begin{abstract}
Aggregate shocks in demand such as the burst of the 2001 dot-com bubble affect firms' behavior and, therefore, the market structure. This paper proposes a fully dynamic oligopoly model to evaluate the impact of aggregate demand shocks on entry and exit costs as well as on investment and labor adjustment costs in IT services. The empirical application builds on an eight year panel dataset that includes every IT service firm in Sweden. The paper finds higher fixed investment and labor adjustment costs for software but lower for operational services after the dot-com bust. The entry costs for software were six times lower than for operational services, which might explain the large number of entrants in software. Entrants are found less productive than incumbents and net exit contributed the most to productivity growth in the IT services after the dot-com bust. For policy makers, the changes in cost structure give key information about industry dynamics and its impact on high-skilled jobs.
\end{abstract}

Keywords: IT services; Imperfect Competition; Dynamic Estimation; Industry Dynamics; Strategic Interactions

JEL Classification: L86, L13, L44, L52, C1, C3, C5, C7

*I would like to thank Dan Ackerberg, Richard Friberg, Christos Genakos, Guofang Huang, Eirik Kristiansen, Nancy Lutz, Lennart Hjalmarsson, Cristian Huse, Espen Moen, Matilda Orth, Ariel Pakes, and Catherine Schaumans for very useful comments. I would also like to thank participants at Knowledge for Growth: European Strategies in the Global Economy (Toulouse), Advancing the Study of Innovation and Globalization in Organizations (Nuremberg), XXIV Journadas de Economia Industrial (Vigo), Nordic Workshop in Industrial Organization (Bergen), Swedish National Conference (Lund), IIOC (Boston), Nordic Econometric Society (Arhus), EEA-ESEM (Oslo), Royal Economic Society (University of Cambridge). and EARIE(Rome) for helpful comments and suggestions.

${ }^{\dagger}$ University of Gothenburg and Research Institute of Industrial Economics, Box 640, SE 405 30, Göteborg, Sweden, Phone +46-31-786 4866, Fax: +46-31-786 4154, E-mail: florin.maican@economics.gu.se 


\section{Introduction}

Services have contributed about 80 percent of GDP growth since 1985 in developed countries. ${ }^{1}$ The IT industry contributes significantly to increased productivity and improved service quality in virtually all sectors of the economy (Jorgenson et al., 2005, 2008). The biggest challenge is to understand the dynamics of this industry where the well functioning of domestic markets become a key factor for overall performance of an economy. The IT services are labor intensive and require skilled workforce, quality of education and research funding to be globally competitive. The access to skilled workforce at the right cost is a key factor in IT services. ${ }^{2}$ Little work, however, deals with the impact of aggregate shocks on firms' productivity and cost structure in labor intensive business services such as IT services. ${ }^{3}$ Being affected differently by negative aggregate shocks in demand, such as the 2001 dot-com bust, firms change their behavior. Changes in firms' behavior regarding adjustments in investment and labor affect the market structure dynamics. Using a fully dynamic oligopoly model, this paper investigates the impact of the 2001 dot-com bust on costs of entry and exit, labor adjustment, and investment in Swedish IT services - an industry characterized by substantial entry and exit.

The paper contributes to the previous literature by recovering both investment and labor adjustment costs in an innovative service industry before and after an aggregate negative demand shock. The changes in cost structure after a negative demand shock are the result of the net effect that appears from two channels. First, firms try to reduce the cost and focus on finding new markets (additional demand). Second, firms can benefit from various governmental policies that aim

\footnotetext{
${ }^{1}$ International Labor Organization (http://www.ilo.org) and McKinsey Global Institute Analysis (http://www.mckinsey.com/mgi/)

${ }^{2}$ For example, countries with high IT services growth - such as India, Ireland and Israel have a pool of skilled engineers available at a globally competitive cost.

${ }^{3}$ Lerner and Schankerman (2010) survey the recent literature on open source and economic development.
} 
to help them in difficulty, e.g., subsidies and labor market policies. ${ }^{4}$ Apart from retail, there are few studies that look into the dynamics of the services industries where it is important to allow for serially correlated differences among firms and estimate adjustment costs. To my knowledge, this is also the first paper that analyzes productivity dynamics at the firm level in IT services and provides estimates for demand elasticities and mark-ups for the IT services sub-sectors. The findings give information about the cost differences across sub-sectors and size groups of IT services firms that can be used, e.g., when subsidies are allocated for different groups of firms in this industry. For policy makers, the changes in cost structure give key information about industry dynamics and its impact on high-skilled jobs. The setup costs contain information about investment behavior of IT firms.

IT markets confirm strong recovery after the 2001-2003 slowdown (Figure 1). ${ }^{5}$ The IT services industry, including software, has the highest contribution to total IT growth (Figure 2), e.g., 5.8 percent for software and 5.3 percent for operational services, maintenance, and repair. ${ }^{6}$ IT services are considered sophisticated because the products are often highly user-specific and non-standardized. The impact of aggregate shocks and various policy choices in this industry affect growth in the local geographical markets and market structure dynamics. Adjustments in labor might be costly if IT firms have to invest in redesign or have to change their service practices to suit new customers. The direct cost of hiring a new employee is likely smaller than the cost involved in direct work with a new environment, i.e., there is an unobserved cost when firms hire a new employee. For small tasks,

\footnotetext{
${ }^{4}$ I cannot separate these effects due to data constraints.

${ }^{5}$ While Western European IT markets were expected to grow at an annual average rate of 6.1 percent until 2008, the Central and East European markets were expected to grow by 13 percent (EU ICT Task Force Report, 2006). Figure 1 presents the evolution of the Western European ICT market growth from 1997 to 2007.

${ }^{6} \mathrm{EU}$ market growth in this sector is principally driven only by computer services. The EU IT market growth by segment in 2007 was as follows: software 5.8 percent, IT services 5.3 percent, computer hardware 2.4 percent, telecommunications equipment 2.0 percent, and carrier services 1.6 percent. IT services are highly dynamic due to the outsourcing of IT functions. The security of IT systems remains an important sector segment.
} 
IT firms might hire external consultants and, therefore increase fixed labor costs. Local demand is the main factor for growth in IT services. ${ }^{7}$ The IT services firms are clustered around large cities that are characterized by dynamic labor markets. Some IT services grow faster in some regions than in others, i.e., there are some sources of exogenous variation (from local markets) in firms' incentives to invest in labor and capital. The Swedish IT services analyzed include all firms in software, operational services, and maintenance and repair from 1996 to 2002. About 25 percent entered and 12-18 percent exited the market during the period. The Swedish IT services market is representative of a majority of all IT markets in the EU. The direct effect of the dot-com bust was a decrease in the labor productivity dispersion, which was caused by an increase in the 25th percentile and a decrease in the 75 th percentile. $^{8}$

The theoretical framework is based on the Markov Perfect Equilibrium (MPE) framework of Ericson and Pakes (1995). Ericson and Pakes' framework assumes that firms make competitive investments that increase their productivity. ${ }^{9}$ IT services is a competitive sector where firms aim to improve their performance by increasing productivity and offering better quality or low-price goods and services, i.e., expanding demand of their services. Since prices and other more detailed product characteristics data on the IT services are not available in many datasets,

\footnotetext{
${ }^{7}$ For example, public defence spending has been an important source for expanding software capabilities in U.S. and Israel. In Norway and Singapore, domestic firms are involved in egovernmental solutions. Software research activities are financed through public innovation funds and research grands in different countries, e.g., U.S., Sweden and South Korea. International companies are an important source of IT services demand. The revenues from software increased more that 3 times between 1995 and 2008 in Ireland. The Ireland's Industrial Development Authority set up a program to attract labor-intensive service businesses to Ireland in the 1980s. Because of tax and financial incentives and educated workforce, multinational companies such as IBM, Microsoft, Oracle, Corel, Symantec, EDS moved part of their operations to Ireland.

${ }^{8}$ There is also an increasing in competitive pressure as the effect of aggregate demand shocks. Recent theoretical contributions discussing the effect of competitive pressure are Schmidt (1997), Boone (2000), Raith (2003); whereas recent empirical contributions include Nickell (1996), Syverson (2004), Aw et al. (2003), Maican (2010), Aghion et al. (2009), and Kretschmer et al. (2012).

${ }^{9}$ Ackerberg et al. (2008) and Pakes (2008) review recent methodological developments in the empirical literature of imperfectly competitive markets.
} 
an accurate estimation of the quality of firms' services can not be obtained from a demand model. Instead, this paper estimates firms' productivity and assumes that there is a direct link between productivity and quality, i.e., a highly productive firm offers high-quality services. Because perceptions of quality differ from person to person and from software to software, it is difficult to define quality in the software industry. When we are able to define quality for a software component, quality varies with the environment and users (Jones and Bonsignour, 2011). ${ }^{10}$ Firm productivity is estimated using an extension of Olley and Pakes (1996) framework suitable for service industries, i.e., it allows for lumpy investment and controls for unobserved prices and selection. ${ }^{11}$ Since labor is a key factor for service quality in the IT industry, productivity is backed out from labor demand (Doraszelski and Jaumandreu, 2009; Maican and Orth, 2009).

This paper uses a two-step procedure to recover the costs structure (Bajari et al., 2007)-BBL. I assume that all relevant features of the IT services industry are part of a state vector that includes firms' perceived levels of productivity, local market demographics, and private shocks to profits. Firms receive states that depend on the payoffs in the product market. Firms' actions are subject to idiosyncratic shocks that are treated as private information, and they choose strategies that maximize their discounted profits, given the expected strategies of their rivals. The paper recovers both revenues and optimal policy functions for investment and labor consistent with the underlying model. The theoretical model is then used to simulate market outcomes with the cost structures before and after the dot-com bust. ${ }^{12}$ I model fixed adjustment labor and capital costs to depend

\footnotetext{
${ }^{10}$ Jones and Bonsignour (2011) analyze the cost and economics of software quality and their relationship to business value. They provide a detailed discussion regarding the challenges of measuring quality in the software industry.

${ }^{11}$ Bartelsman and Doms (2000) and Syverson (2011) survey empirical work on productivity changes using micro data.

${ }^{12}$ Understanding how different ways to obtain perturbed policy functions affect the market structure plays a crucial role in simulations. For example, we might generate policies that imply negative investments that make firms exit early.
} 
on the likelihood to adjust positively or negatively, and this propensity for adjustment depends on firms' state variables (Ryan, 2012). ${ }^{13}$ This allows me to evaluate the adjustment costs for each IT firm after the structural parameters are identified.

Recent empirical literature uses the BBL approach in a similar context (Beresteanu and Ellickson, 2006; Gowrisankaran et al., 2010; Ryan, 2012; Ryan and Tucker, 2006; Sweeting, 2007). ${ }^{14}$ Goettler and Gordon (2012) use a dynamic oligopoly model that endogenize innovation to analyze the impact of competition on innovation in the personal computer microprocessor industry. Pakes et al. (2007a) (POB), Aguirregabiria and Mira (2007), and Pesendorfer and Schmidt-Dengler (2003) develop alternative extensions to the Hotz and Miller (1993) approach to estimate dynamic games where actions have a discrete choice structure. Dunne et al. (2009) use the basic POB framework (no differentiation) to study entry, exit and the determinants for markets structure for two U.S. service industries, dentists and chiropractors. My model allows for differentiation and serially correlated differences among firms and controls for selection.

By estimating firms' productivity controlling for imperfect competition and local market characteristics, productivity is the only serially correlated state variable that helps for consistency in estimation of continuation values and policy functions in case of fully dynamic models. Controlling for selection when estimating productivity is important in the IT industry. The exit and entry in my data are based on organizational number. ${ }^{15}$ There is a high likelihood of sell-offs of small firms to large firms since small firms have been successful. IT services offer specialized

\footnotetext{
${ }^{13}$ Pakes et al. (2007b) and Pakes (2010) show how the inequalities generated by behavior choice models can be used as a basis in estimation.

${ }^{14}$ Ryan (2012) evaluates the welfare costs of the 1990 Amendaments to the Clean Air Act on the US Portland cement industry using a dynamic model of oligopoly in the tradition of Ericson and Pakes (1995). Benkard (2004) examines the wide-body aircraft industry but does not recover estimates of fixed costs. Gowrisankaran et al. (2010) evaluate the impact of the Medicare Rural Hospital Flexibility (Flex) Program.

${ }^{15} \mathrm{~A}$ so-called organization number specifies the identity of a corporate body. The Swedish Tax Authority (Skatteverket) has a register of all organization numbers used for tax reporting.
} 
product services, and improved use of novel IT tools can raise the average prices and, therefore, increase revenues and productivity. However, since price variation in IT services can also be due to local market power or other demand shocks, it is important to control for demand when estimating productivity in this industry.

I find that the estimated elasticity of demand for the software industry is about -4.6, i.e., a mark-up of 1.277. For grouped operational services and maintenance firms, the estimated demand elasticity is about -5.96 , yielding a mark-up of 1.52 . For software, the productivity growth was around 21 percent from 1997 to 2000, but only about 6 percent from 1997 to 2002. After the 2001 dot-com bust, exit firms contributed more to productivity growth (12 percent) than continuing firms (7.5 percent). For operational services and maintenance, the productivity growth was about 70 percent from 1997 to 2000 and about 32 percent from 1997 to 2002. In the period 1997-2000, almost all productivity growth came from continuing firms. ${ }^{16}$ However, exit firms contributed the most (50 percent) to productivity growth from 1997 to 2002. This emphasizes the importance of the selection effect in this industry. Entrants are found less productive than continuing firms.

On average, the impact of the 2001 dot-com bust on revenues was a decrease of about 20 percent for software and operational services and of about 34 percent for maintenance and repair. Furthermore, firms reduced the number of employees by about 25 percent. After the dot-com bust, firms were more likely to exit in all sub-sectors. I also find that foreign IT firms were more likely to exit. The geographical location of owing firm has been found to be more important for productivity growth than the location of IT firms (Bloom et al., 2012). ${ }^{17}$ For software and operational services, I find that foreign IT firms have about 19 percent higher

\footnotetext{
${ }^{16}$ Jorgenson et al. $(2005,2008)$ find higher productivity growth in IT-producing industries than in IT-using industries.

${ }^{17}$ They find that productivity from IT capital plays a key role in explaining higher productivity of US-based multinationals operating in the EU compared to EU-based firms. This advantage is explained by the evidence of complementarity between IT capital and human resources.
} 
revenues than domestic IT firms.

The impact of dot-com bust on investment and labor adjustment costs varies significantly depending on firm productivity and firm size. Lower adoption and smaller size IT investments in Europe are found to be responsible for the lower productivity growth in Europe than in the US over 1990s (van Ark et al., 2008). My findings suggest that fixed and variable adjustment costs are important determinants of investment and labor decisions. In addition to the lack of demand, they also explain the downturn in productivity after the dot-com bubble. When there are fixed costs, a static evaluation ignores important economic penalties associated with the dot-com bust costs.

The paper finds that, after the burst of the 2001 dot-com bubble, there was an increase in fixed (setup) investment costs for software but a decrease for operational services and maintenance and repair firms. From 2000 to the end of the studied period, there were higher fixed costs for positive labor adjustment for software compared to 1996-1999 (about 4 times), lower for operational services (about 4 times), and about the same for maintenance and repair. For negative labor adjustment, the findings indicate higher fixed costs for software but lower for operational services after the dot-com bust. I find that the entry costs for software were six times lower than for operational services, which might explain the large number of entrants in software. In addition, while firms in software and operational services had higher scrap (sell-off) values after 2000, the maintenance and repair firms had lower scrap values.

The paper is organized as follows. Section 2 gives a brief overview of the Swedish IT services industry and relevant events over the last 10 years. It also includes a discussion on the data sources. Section 3 presents the theoretical model and Section 4 discusses the estimation details. The empirical results are presented in Section 5, whereas Section 6 concludes the paper. 


\section{Overview of the Swedish IT Services Industry}

The Swedish IT industry is in better shape than it has been for many years. At the beginning of 2006, IT stocks had a 52 percent 12-month growth rate. The Swedish IT industry had 48 firms among Europe's 500 fastest growers in Deloitte's Technology European Fast 2006. In contrast to the late 1990s IT boom profit growth continues to rise due to better business models and high demand.

Data. This paper draws on a census of the Swedish IT services industry, provided by Statistics Sweden, Financial Statistics(FS) and Regional Labor Statistics (RAMS). The Swedish industrial classification code (SNI) for this industry is 72. ${ }^{18}$ The IT services industry includes the following subgroups: hardware consultancy (code 7210); software consultancy (code 7220) - customized software and packages software; data processing (code 7230); database activities (code 7240); maintenance and repair of office, accounting and computing machinery and data processing equipment (code 7250); and operational service activities (code 7260). Because it is difficult to divide IT consultancy services for hardware and software, I keep them in one group called software. In addition, there are few observations for hardware consultancy. On the other hand, data processing, database activities, and other computer-related services can be grouped into operational service activities. ${ }^{19}$ New firms have appeared while others have exited or merged. FS contains information on firm input and output and RAMS contains information on employee education and wages. The dataset covers the period 1996-2002. A

\footnotetext{
${ }^{18}$ The SNI standard builds on the Statistical Classification of Economic Activities in the European Community (NACE).

${ }^{19}$ Statistics Sweden (SCB), a Swedish government office, also uses this grouping.
} 
unit of observation is a firm with one or many establishments. ${ }^{20}$ The computer consultancy was affected by some major changes in the last few years of the period. It is important to note that large firms can have many subsidiaries in the same sector, although I cannot observe this in my data. Appendix A provides additional information on the data and variable definitions.

According to the Swedish Business Statistics 1999, the Swedish industrial classification group 72 consists of 19,045 establishments (5,625 firms in my data) and around 71,000 employees (Table 1). The total net turnover was SEK 83.3 billion and value added was SEK 38.3 billion (values are 1996 SEK). Table 1 presents characteristics of the Swedish IT services during 1996-2002. From 1996 to 2002 at the industry level, the number of firms grew by 60 percent, the industry valueadded by 100 percent, the number of employees by around 100 percent as well, total wages by 147 percent, and investments by 99 percent. Most of the growth occurred from 1996 to 2000. From 2000 to 2001 at the industry level, the number of firms grew by 3 percent, value-added by 22 percent, wages by 15 percent, the number of employees by 10 percent, and investments by 8 percent. However, the burst of the 2001 dot-com bubble induced a negative growth of about 2 percent in number of firms, about 8 percent in value-added, about 7 percent in total wages and labor, and 10 percent in investment.

Software consultancy is the sub-sector with the largest share of firms, employees, turnover and value added in relation to the total value for each of these variables, e.g., there are about 10 times more firms active in software than in operational services (Panels B and C). Software has net entry over the study period and the largest numbers of entrants $(1,532)$ and exits $(1,017)$ in 2000. Operational services had net entry until the burst of the 2001 dot-com bubble. Maintenance

\footnotetext{
${ }^{20}$ In my data, I do not observe if a firm has establishments (offices) in different regions. If they have, it is most likely that each establishment pays local taxes. Therefore, I assume that each establishment is independent, i.e. it is treated as a separate firm. If there are several establishments of the same firm in a local market, they might be reported as one establishment.
} 
and repair is the smallest sub-sector - about 110 firms.

Table 2 shows the impact of the 2001 dot-com bust on the growth rates by sub-sector between 2000-2001 and 2001-2002. The IT sub-sectors were affected differently. Operational service firms were more affected between 2000-2001, e.g., the number of firms decreased by around 20 percent, sales by 27 percent, and investments by 19 percent. Software firms were most affected from 2001 to 2002, i.e., sales decreased by 18 percent and investments by 10 percent.

IT service firms are also found in the following sectors: retail trade in computers; office machinery and equipment wholesale; and telecom products and electronic components wholesale. It is hard to specify the activities of these firms, and foreign market is important for them. Therefore, they are not included in the study. ${ }^{21}$ They represent 0.2 percent of the total number of companies and their net turnover represents 41 percent of the total net turnover in the industry. Apart from analyzing different sub-sectors, the paper also groups the firms into three classes according to number of employees: (i) small - 0-19 employees; (ii) medium - 20-99 employees; and (iii) large - over 100 employees.

In Sweden, IT services are concentrated to the three largest cities, i.e., Stockholm, Gothenburg, and Malmö. The Swedish government focuses on the IT sector and pays close attention to firm entry and exit. ${ }^{22}$ Lundmark (1995) studies the patterns of growth and location of computer services in Sweden. More specifically, he analyzes location patterns of IT services in local markets. He emphasizes that the market structure of Swedish IT services is characterized by a large degree of local and regional sales, indicating the importance of proximity to customers. The

\footnotetext{
${ }^{21}$ However, the share of total turnover in the sectors that represents IT consultancy activities cannot be determined from the survey or from Swedish Business Statistics in 1999.

${ }^{22}$ The Swedish Agency for Economic and Regional Growth (NUTEK) contributes to the creation of new enterprises, more growing enterprises, stronger regions, and consequently to promote sustainable economic growth and prosperity throughout the country. Another Swedish government agency for innovation, Vinnova, elaborates strategies and forms reference groups with key players from the industry, government agencies, and universities to improve the competitiveness of the IT industry.
} 
Swedish IT industry is characterized by large heterogeneity. Most of the firms are small - around 90 percent of the firms in my data had fewer than 20 employees in 2000. Yet, despite the large proportion, small firms only generated about 25 percent of total employment and sales in 2000. Therefore, large firms that operate on both national and international markets are important for the overall performance.

Market definition. Information is what is demanded in the IT services industry. How much and from who depend on the type of activity carried out (in Sweden), price, training effort, and the level of learning. ${ }^{23}$ Statistics Sweden (SCB) conducted a survey about demand structure in the Swedish IT services industry in 2001. They found that the customers of Swedish IT services are as follows: firms and public utilities around 76 percent; central government and municipal authorities 14 percent; households and individuals 0.2 percent; and exports around 10 percent. Only firms that are in the SNI group 72 were included in the survey. The customers of small firms are households and private individuals. Large and medium IT firms commonly have business enterprises as customers. While large companies dominate the Swedish IT services in terms of market share, small and medium companies dominate the market with respect to number of firms. ${ }^{24}$ Moreover, 50 percent of firms say that 75-100 percent of their sales come from neighboring municipalities and 35 percent of firms do not make sales in neighboring municipalities.

The paper uses Statistics Sweden's county definition to define markets. A county consists of a collections of municipalities. This classification groups the Swedish municipalities (290) into 25 markets that are mutually exclusive and ex-

\footnotetext{
${ }^{23}$ Bower (1973) discusses the specificity of demand in IT services.

${ }^{24}$ Firms that are in other SE-SIC 92 groups and provide IT services are not included in the survey due to the difficulties in measuring their activities. Cerda and Glanzelius (2003) provide more details about Swedish IT services.
} 
haustive of the land mass of Sweden. ${ }^{25}$ The county-based market definition is a compromise between contradictory requirements. The theoretical model assumes that IT service markets are isolated geographic units; firms in one market interact competitively only with other firms in the same county market. Firms placed in too large markets may not all respond to the same market forces (external or actions of industry competitors). Counties are a suitable compromise to resolve the tension between isolating markets yet ensuring that the IT service firms within them are interconnected. IT service firms should, however, be close to their customers. Large firms in this sector may face international competition if they sell software, for example. The definition of the market does not affect the productivity results. I only include IT firms that have at least a part of their revenues from the Swedish market when I estimate the cost functions.

Tables 3 and 4 present the summary statistics at the local market level for the Swedish IT service industry from 1996 to 2002, for all firms (Table 3) and grouped by size (Table 4). An average local market (county) has about 255 IT service firms; 3,100 employees; 7,225 non-IT firms; and a population of about 400,000 people (Table 3). Table 4 shows that an average market has about 230 small, 22 medium, and about 7 large IT firms. The counties that include Stockholm, Gothenburg, or Malmö have about 10 times more firms than does an average county (Table 4).

Having access to detailed data on individual counties and information on demand based on surveys, demographic characteristics, population and number of firms (other than IT service firms) are good proxies for local demand.

\footnotetext{
${ }^{25}$ Statistics Sweden provides more detailed information, www.scb.se.
} 


\section{The modeling approach}

To evaluate the impact of 2001 dot-com bust on cost structure it is necessary to have a theoretical model of the IT services industry. The model builds on the work of Ericson and Pakes (1995), who provide a theoretical framework of industry dynamics on imperfectly competitive markets. The model considers the main characteristics of the IT industry. First, the dynamic aspect, characterized by simultaneous entry and exit, is one of main characteristics of IT industry. Second, investment and labor decisions account for the characteristics of the local markets (counties). The distribution of capacities (IT labor) and the industrial structure are primarily determinants of local market structure. Third, there is substantial heterogeneity in IT services. Skilled labor, demand, and the efficiency of using new technologies play a key role. Fourth, investments in knowledge and technology change the quality of IT services and firms pay both fixed and variable adjustment costs.

State space. All economically important characteristics of firms are incorporated into a state vector that includes productivity (efficiency), market demographics, and a set of private information payoff "shocks" that affect firms' payoffs. The vector $s$ groups firms' state variables. Firms receive state-dependent revenues from the product (service) market in each period. Entry, exit, and investments in labor and technology influence the evolution of the state vector. The most important component of the state space is productivity, $\omega$. Firm $j$ 's productivity, $\omega_{j t}$, is not directly observable in the data, but is obtained by estimation of a value-added generating function model. This paper assumes that the productivity evolves stochastically according to a first-order Markov process:

$$
\omega_{j t}=\tilde{g}\left(\omega_{j t-1}\right)+\xi_{j t},
$$


where $\xi_{j t} \in N\left(0, \eta^{\omega}\right)$ and $\tilde{g}(\cdot)$ is an unknown function. Thus, firms' actual productivity $\omega_{j t}$ in period $t$ can be decomposed into expected productivity $\tilde{g}\left(\omega_{j t-1}\right)$ and a private productivity shock $\xi_{j t}$. The productivity shock $\xi_{j t}$ may be thought of as the realization of uncertainties that are linked to productivity. The conditional expectation function $\tilde{g}(\cdot)$ is unobserved by the econometrician (though known to the firm), but it can be estimated nonparametrically. Furthermore, I assume that $\omega_{j m t}$ evolves independently across markets.

Each local market $m$ is defined by its characteristics: the total number of firms (other than IT) and population. Because high correlation between the population and the number of firms (about 0.98), I only use the number of firms in the empirical part. The number of non-IT firms evolves according to the following $A R(1)$ process:

$$
\text { firms } s_{m t}=\delta_{1}^{\text {firms }} \text { firms }_{m t-1}+\delta_{0}^{\text {firms }}+v_{m t}^{\text {firms }}, \text { where } v_{m t}^{\text {firms }} \sim N\left(0, \eta^{\text {firms }}\right) .
$$

Timing assumptions. There is a number of IT firms in a set of markets in an infinite sequence of years. In each year, the timing of the game is as follows:

1. Each firm observes its current firm productivity and market demographics.

2. Each potential entrant receives a draw from the distribution of entry values and makes its entry decision; each incumbent firm makes its investment decision.

3. Each firm receives a private shock and then firms compete in the product market.

4. Each incumbent that chooses to leave the market exits and receives its scrap payment; each entrant pays its entry fee. Firms decide on investments in labor and capital without knowing the decisions of their competitors. 
5. The state vector adjusts and firms enter and exit.

Firms observe the state variables at the beginning of each period along with the entry, exit, investment, and production decisions of their rivals in the previous period. Private information shocks are drawn independently across firms and periods from a known distribution. Firms do not update their expectations of future behavior after observing the actions of their rivals.

Equilibrium concept. Equilibrium is obtained when firms follow strategies that maximize the expected discounted present value of their stream revenues given the expected strategies of the competitors. The paper assumes that firms' strategies depend only on the current state vector and generate a Markov Perfect Nash Equilibrium (MPNE). The MPNE consists of a set of best response strategies governing entry, exit, labor, and investment. Firm $j$ makes decisions regarding, e.g., entry, exit, and investments collectively denoted by $d_{j}$. Since the full set of dynamic Nash equilibria is unbounded, I restrict firms' strategies to be anonymous, symmetric, and Markovian. Therefore, a firm's strategy, $\sigma_{j t}$, can be written as a mapping from states to actions:

$$
\sigma_{j t}:\left(s, \epsilon_{j t}\right) \rightarrow d_{j t},
$$

where $\epsilon_{j t}$ is the firm's private information about the cost of entry, exit, investment, and labor. A vector of strategies is a mapping of the current state of the system for each firm's strategy. The time horizon is infinite, payoffs are bounded, firms have Markovian strategies, and the discount factor $\beta$ is positive and less than one. The value of a firm in state $\mathbf{s} \in S$ is

$$
V_{j}(\mathbf{s} \mid \boldsymbol{\sigma}(\mathbf{s}))=E_{\epsilon_{j}}\left[\pi_{j}\left(\boldsymbol{\sigma}(\mathbf{s}, \boldsymbol{\epsilon}), \mathbf{s}, \epsilon_{j}\right)+\beta \int V_{j}\left(\mathbf{s}^{\prime} \mid \boldsymbol{\sigma}\right) d P\left(\mathbf{s}^{\prime} \mid \boldsymbol{\sigma}(\mathbf{s}, \boldsymbol{\epsilon}), \mathbf{s}\right)\right],
$$


where $\boldsymbol{\sigma}(\mathbf{s})$ is the vector of strategies, $\pi_{j}(\cdot)$ is the per-period profit function, and $P(\cdot)$ is the conditional probability distribution governing the transition between states. A strategy profile $\boldsymbol{\sigma}(\mathbf{s})$ is an MPNE giving competitors profile $\boldsymbol{\sigma}_{-j}(\mathbf{s})$ if each firm $j$ prefers strategy $\sigma_{j}(\mathbf{s})$ to all Markov strategies $\sigma_{j}^{\prime}(\mathbf{s})$ :

$$
V_{j}\left(\mathbf{s} \mid \sigma_{j}(\mathbf{s}), \boldsymbol{\sigma}_{-j}(\mathbf{s})\right) \geq V_{j}\left(\mathbf{s} \mid \sigma_{j}^{\prime}(\mathbf{s}), \boldsymbol{\sigma}_{-j}(\mathbf{s})\right)
$$

for all $j, \mathbf{s}$, and $\sigma_{j}^{\prime}(\mathbf{s})$. In a similar setting, Doraszelski and Satterthwaite (2010) discuss the details on existence and uniqueness of of pure strategy equilibrium. The existence of private information $\epsilon_{j}$ guarantees that there is at least one pure strategy equilibrium.

There are two assumptions on the dynamic framework. First, the equilibrium might not be unique, but I assume that the same equilibrium is played in each local market (Bajari et al., 2007). Second, I assume that there are no structural changes in the IT business environment. It implies that I do not need to model the beliefs of the IT firms about the distribution of future changes in the business environment.

I describe each component of the model in detail in the section 4 by deriving the ex-ante value functions for potential entrants and incumbents. These value functions are used in the counterfactual simulations when the costs of the dot-com bust are evaluated.

\section{Estimation}

The estimation is made in two steps. In the first step, I estimate a value added generating function to obtain an estimate of firms' perceived productivity. Knowing how the state space evolves over time, the revenue generating function and the 
policy functions can be estimated. Estimated policy functions describe the optimal strategy profile for each firm. In the second step, I estimate the structural parameters governing fixed and variable investment costs, scrap values, and sunk costs.

Firm productivity. The present paper assumes a Cobb-Douglas technology where IT service firms sell a homogeneous product (at the subsector level) and that the factors underlying profitability differences among firms are neutral efficiency differences. ${ }^{26}$ The lack of detailed information about services of each IT firm does not allow to model product differentiation using a discrete choice demand model. For this reason, estimation of the value-added generating function requires the homogeneity assumption.

Allowing for heterogeneity in productivity in the dynamic model makes this assumption not so restrictive. The services production function can be specified as

$$
q_{j t}=\beta_{0}+\beta_{l} l_{j t}+\beta_{k} k_{j t}+\omega_{j t}+u_{j t}^{p}
$$

where $q_{j t}$ is the log of service output sold by firm $j$ at time $t ; l_{j t}$ is the log of labor input, i.e., number of employees (full-time adjusted) ; and $k_{j t}$ is the log of capital input. The unobserved factor $\omega_{j t}$ measures productivity, and $u_{j t}^{p}$ is either measurement error (which can be serially correlated) or a shock to production that is not predictable during the period in which labor can be adjusted.

Specification (5) assumes that prices are constant across firms. When firms have some market power, prices set by individual firms influence the estimated productivity. The negative correlation between input and prices leads to underestimation of the labor and capital parameters in the production function (De Loecker, 2011; Klette and Griliches, 1996; Melitz, 2000). If the services are perfect substi-

\footnotetext{
${ }^{26}$ The first-order Taylor approximation of a nonparametric function is the Cobb-Douglas function in the logarithmic form.
} 
tutes, deflated sales are a perfect proxy for unobserved quality adjusted output. Following the recent literature, it is possible to correct for unobserved price bias in value-added generating function by introducing a simple CES demand function:

$$
p_{j t}=p_{I t}+\frac{1}{\eta} q_{j t}-\frac{1}{\eta} q_{I t}-\frac{1}{\eta} \lambda_{j t}
$$

where $p_{j t}$ is output price, $p_{I t}$ and $q_{I t}$ are IT service output price index and quantity at the industry level, $\lambda_{j t}$ are shocks to demand. ${ }^{27}$ The demand specification assumes that firms operate in a market with horizontal product differentiation, where $\eta(<-1$ and finite) captures the elasticity of substitution among IT services. Due to data constraints, the demand system is quite restrictive, implying a single elasticity of substitution for all IT services and that there are no differences in cross price elasticities.

I decompose demand shifters into observed local market characteristics $\mathbf{z}_{m t}$, i.e., number of non-IT firms and population, and unobserved demand shock $u_{j t}^{d}$ :

$$
\lambda_{j t}=\mathbf{z}_{m t}^{\prime} \boldsymbol{\beta}_{z}+u_{j t}^{d}
$$

where $u_{j t}^{d}$ are i.i.d. shocks to demand. ${ }^{28}$ Therefore, it is not possible to use a more sophisticated demand model that allows for product differentiation (Berry, 1994; Berry et al., 1995; Nevo, 2001). Since the IT service prices of individual firms are unobserved, the deflated output is defined as $y_{i t}=q_{i t}-p_{I t}$. Firm productivity follows a first-order Markov process (equation 1) and takes the following form:

\footnotetext{
${ }^{27}$ There is no price index for IT services from 1996 to 2002. From 2002, Statistics Sweden has started to construct a price index for IT services. In the empirical part, I use the consumer index price. For robustness, I have constructed a backward price index (1996-2002) from new IT services price index (2002-2009). Even if this construction is problematic (small sample errors) it can be informative. Because there are no substantial changes in the elasticities, the results are not reported.

${ }^{28}$ If $u_{j t}^{d}$ are correlated unexpected shocks, they enter into productivity measure (Levinsohn and Melitz, 2006).
} 
$\omega_{j t}=\tilde{g}\left(\omega_{j t-1}\right)+\xi_{j t}$. Controlling for price and demand shocks in the value-added generating function (5) yields

$$
\begin{aligned}
y_{j t}= & \left(1+\frac{1}{\eta}\right)\left[\beta_{0}+\beta_{l} l_{j t}+\beta_{k} k_{j t}\right]-\frac{1}{\eta} q_{I t}-\frac{1}{\eta} \mathbf{z}_{m t}^{\prime} \boldsymbol{\beta}_{z}+g\left(\omega_{j t-1}\right)+\left(1+\frac{1}{\eta}\right) \xi_{j t} \\
& -\frac{1}{\eta} u_{j t}^{d}+\left(1+\frac{1}{\eta}\right) u_{j t}^{p}
\end{aligned}
$$

where $g(\cdot)=\left(1+\frac{1}{\eta}\right) \tilde{g}(\cdot)$. The value of $k_{j t}$ is determined by previous investment $i_{j t-1}$. Labor $l_{j t}$ is correlated with the shocks in productivity $\xi_{j t}$. The inverse labor demand helps us to recover unobserved productivity $\omega_{j t-1}$ rather than recovering from the unknown policy function of investment (Olley and Pakes, 1996) and materials (Levinsohn and Petrin, 2003). ${ }^{29}$ Doraszelski and Jaumandreu (2009) propose one-step estimator that uses the parametric form of the labor demand function from the Cobb-Douglas production function to proxy for productivity. Maican and Orth (2009) discuss the identification of the production function using nonparametric and parametric labor demand function. ${ }^{30}$ The main advantage of using labor demand function is that the observations with zero investments are included in the analysis. This is notable because IT firms often invest one year, followed by several years without investment. In year $t-1$, firms chose current labor $l_{j t-1}$ based on current productivity $\omega_{j t-1}$, which gives demand for labor as

$$
l_{j t-1}=\frac{1}{1-\beta_{l}}\left[\beta_{0}+\ln \left(\beta_{l}\right)+\beta_{k} k_{j t-1}+\omega_{j t-1}-\left(w_{j t-1}-p_{j t-1}\right)+\ln \left(1+\frac{1}{\eta}\right)\right],
$$

where $w_{j t-1}$ is total wages paid. Solving for $\omega_{j t-1}$ yields

$$
\begin{aligned}
\omega_{j t-1}= & \frac{\eta}{1+\eta}\left[\delta_{0}+\left[\left(1-\beta_{l}\right)-\frac{1}{\eta} \beta_{l}\right] l_{j t-1}+w_{j t-1}-p_{I t-1}-\left(1+\frac{1}{\eta}\right) \beta_{k} k_{j t-1}\right. \\
& \left.+\frac{1}{\eta} q_{m t-1}+\frac{1}{\eta} \mathbf{z}_{m t-1}^{\prime} \boldsymbol{\beta}_{z}\right],
\end{aligned}
$$

\footnotetext{
${ }^{29}$ Ackerberg et al. (2006) (ACF) discuss the identification of the production function using different proxies.

${ }^{30}$ They also discuss the identification in the production function when labor has dynamic implications.
} 
where $\delta_{0}=-\ln \left(\beta_{l}\right)-\ln (1+1 / \eta)-\beta_{0}(1+1 / \eta)-\ln E\left[e^{u_{j t}^{p}}\right]+\frac{1}{\eta} \ln E\left[e^{u_{j t}^{d}}\right]$. Appendix B presents the productivity estimation details using one-step estimator. This estimator requires the following assumptions: (i) labor is a static variable input; (ii) capital is a fixed dynamic input chosen in $t-1$; (iii) productivity is the only unobserved variable; (iv) there is helpful variation in firms' wages, and wages are exogenous. ${ }^{31}$ The static assumption of labor might be restrictive in the IT industry. For robustness, I also use a two-step estimator based on ACF and nonparametric labor demand function to proxy for productivity (Maican and Orth, 2009). The results using two-step estimator are consistent with those from onestep estimator. Having the estimated parameters for the value-added generating function, we can recover the productivity (efficiency) for each firm.

Static profits. A firm's profits in one period depends on its productivity, $\omega_{j t}$; competitors' productivity, $\boldsymbol{\omega}_{-j t}$; local market characteristics, $\mathbf{z}_{m t}$; and the firm's investment and labor decisions. Therefore, the profit of firm $j$ in period $t$ is

$$
\begin{aligned}
\pi_{j t}\left(\omega_{j t}, \omega_{-j t}, \mathbf{z}_{m t}, \epsilon_{j t} ; \boldsymbol{\beta}, \boldsymbol{\theta}\right)= & \tilde{r}_{j t}\left(\omega_{j t}, \boldsymbol{\omega}_{-j t}, \mathbf{z}_{m t} ; \boldsymbol{\beta}\right)-c_{i}\left(i_{j t} ; \boldsymbol{\theta}^{i}\right) \\
& -c_{\Delta l}\left(\Delta l_{j t} ; \boldsymbol{\theta}^{l}\right)-c_{l}\left(l_{j t}\right)+\epsilon_{j}\left(d_{j}\right)
\end{aligned}
$$

where $\epsilon_{j t}$ denotes the private shocks to profits; $c_{i}\left(\cdot ; \boldsymbol{\theta}^{i}\right)$ the cost associated with investment in technology (machinery); $c_{\Delta l}\left(\cdot ; \boldsymbol{\theta}^{l}\right)$ the cost of adjusting the number of employees; and $c_{l}(\cdot)$ is total labor cost. In the empirical implementation and results, I focus only on the cost of adjusting the number of employees even if I control for the total cost of labor, i.e., to separate revenues from costs. In the forward simulations, the payoff generating function $\tilde{r}_{j t}(\cdot)$ is estimated using the

\footnotetext{
${ }^{31}$ To control for wage endogeneity, one can use lagged wages as instruments.
} 
following form:

$$
\begin{aligned}
r_{j t} & =\beta_{0}+\boldsymbol{\beta}_{1}^{\prime} \mathbf{b s}_{1}\left(\omega_{j t}\right)+\boldsymbol{\beta}_{2}^{\prime} \mathbf{b s}_{2}\left(\sum_{h \neq j} \omega_{h t}\right)+\boldsymbol{\beta}_{3}^{\prime} \mathbf{b s}_{3}\left(k_{j t}\right)+\boldsymbol{\beta}_{4}^{\prime} \mathbf{b s}_{4}\left(\sum_{h \neq j} k_{h t}\right) \\
& +\boldsymbol{\beta}_{5}^{\prime} \mathbf{b s}_{5}\left(\text { firms }_{m t}\right)+\beta_{6} \text { after }_{2000}+\beta_{7} \text { foreign }_{j t} \\
& +\beta_{8} \text { medium }_{j t}+\beta_{9} \text { large }_{j t}+\boldsymbol{\beta}_{m}+\varepsilon_{j t}^{r},
\end{aligned}
$$

where $\mathbf{b s}(\cdot)$ is the basis function of cubic b-splines (Chen, 2007; Coppejans, 2004; Eubank, 1988); $\boldsymbol{\beta}_{m}$ is the set of market effects introduced to capture differences in other unobserved factors that are common across all firms in a market; firms mt $_{\text {is }}$ the number of firms, other than IT, at the market level; medium imt $_{\text {and }}$ arge imt $_{\text {in }}$ are dummy variables for medium and large firms; and $\varepsilon_{j m t}^{r}$ are i.i.d. shocks. ${ }^{32}$

Investment and labor costs. The cost function associated with investment in technology is:

$$
\begin{aligned}
c_{i}\left(i_{j m t} ; \boldsymbol{\theta}^{i}\right) & =1\left(i_{j m t}>0\right)\left(\tilde{\theta}_{0}^{i,+}+\theta_{1}^{i,+} i_{j m t}+\theta_{2}^{i,+}\left(i_{j m t}\right)^{2}\right)+1\left(i_{j m t}<0\right)\left(\tilde{\theta}_{0}^{i,-}+\theta_{1}^{i,-} i_{j m t}\right. \\
& \left.+\theta_{2}^{i,-}\left(i_{j m t}\right)^{2}\right) .
\end{aligned}
$$

Fixed and variable adjustment costs vary separately for positive and negative investments. Setup costs from installing new equipment are covered by the fixed costs, $\tilde{\theta}_{0}$. Fixed costs of investment are private information to the firm and are drawn each period from a known distribution, $F^{i,+}\left(\cdot ; \gamma^{i,+}\right)$. Since the firm can sell old IT equipment, sunk costs associated with negative investment can be positive. These costs are private information and drawn each period from a common distribution, $F^{i,-}\left(\cdot ; \gamma^{i,-}\right)$. The total labor cost is $c_{l}\left(l_{j t}\right)=\theta^{l} l_{j t}$. The cost function

\footnotetext{
${ }^{32}$ I omit to control for aggregate sales/value-added at the local market level in equation (10) because the rival variables based on productivity and capital already capture the local market characteristics. In addition, adding aggregate sales/value-added might introduce endogeneity problems.
} 
associated with labor adjustment is given by:

$$
c_{\Delta l}\left(\Delta l_{j m t} ; \boldsymbol{\theta}^{l}\right)=1\left(\Delta l_{j m t}>0\right)\left(\tilde{\theta}_{0}^{l,+}+\theta_{1}^{l,+} \Delta l_{j m t}\right)+1\left(\Delta l_{j m t}<0\right)\left(\tilde{\theta}_{0}^{l,-}+\theta_{1}^{l,-} \Delta l_{j m t}\right) .
$$

For example search and recruiting, training, explicit firing costs are covered by the $c_{\Delta l}(\cdot)$ function. Reorganization of services and consulting activities are also included. Fixed costs associated with positive and negative labor adjustment are drawn from the distributions $F^{l,+}\left(\cdot ; \gamma^{l,+}\right)$ and $F^{l,-}\left(\cdot ; \gamma^{l,-}\right)$.

Entry, exit, and fixed costs. IT firms also have different costs that are not related to service production. To enter the market, firms pay an entry (sunk) cost, $f_{j}^{e}$. The entry cost is drawn from the common distribution, $F^{e}\left(\cdot ; \gamma_{e}\right)$. Firms that exit the market receive the sell-off value associated with closing down the firm, $f_{j}^{x}$, which is commonly drawn from the common distribution, $F^{x}\left(\cdot ; \gamma_{x}\right)$. Summarizing, the costs that depend on the status of the firm are:

$$
f_{j}(\boldsymbol{\sigma}(\mathbf{s}))=\left\{\begin{array}{cl}
f_{j}^{e} & \text { if the firm is an entrant } \\
f_{j}^{x} & \text { if the firm exits the market. }
\end{array}\right.
$$

The ex-ante value functions for both potential entrants and incumbents can be written down. The value functions that give the expected discounted present value, in Swedish krona (SEK), of being at a given state vector, have two components: ${ }^{33}$ (i) the per-period payoff function and (ii) the continuation value, i.e., the expected value of next period's state. Firms use their value function to find their optimal entry, exit, investment, and labor policies.

The value function for the potential entrant $j$ who decides to enter in the next period conditional on the current state and the draw from the distribution of the

\footnotetext{
${ }^{33}$ At the beginning of the study period (1996), 1 USD=6.71 SEK and 1 EUR=8.63 SEK.
} 
sunk cost of entry, $f_{j}^{e}$, can be written as:

$$
V_{j}^{e}\left(\mathbf{s}, f_{j}^{e}\right)=\max _{i_{j}^{e}, l_{j}^{e}}\left\{-f_{j}^{e}-\tilde{\theta}_{0}^{i}-\theta_{1}^{i} i_{j}^{e}-\theta_{2}^{i}\left(i_{j}^{e}\right)^{2}-\theta_{1}^{l} \Delta l_{j}^{e}+\beta E\left[V\left(\mathbf{s}^{\prime} \mid \mathbf{s}\right)\right]\right\} .
$$

The value function for an incumbent has two parts. The first part corresponds to whether the firm decides to exit the industry. If it does, it receives its servicesmarket payoffs $\pi_{j}(\mathbf{s})$ and its sell-off payment $f_{j}^{x}$. If it remains active, it receives service-market revenues. Therefore, if firm $j$ continues, it obtains the following payoff:

$$
\begin{aligned}
V_{j}^{\text {stay }}(\mathbf{s})= & \max _{i_{j}, l_{j}}-1\left(i_{j}>0\right)\left(\tilde{\theta}_{0}^{i,+}+\theta_{1}^{i,+} i_{j}+\theta_{2}^{i,+}\left(i_{j}\right)^{2}\right) \\
& -1\left(\Delta l_{j}>0\right)\left(\tilde{\theta}_{0}^{l,+}+\theta_{1}^{l,+} \Delta l_{j}\right)-1\left(i_{j}<0\right)\left(\tilde{\theta}_{0}^{i,-}+\theta_{1}^{i,-} i_{j}+\theta_{2}^{i,-}\left(i_{j}\right)^{2}\right) \\
& -1\left(\Delta l_{j}<0\right)\left(\theta_{0}^{l,-}-\theta_{1}^{i,-} \Delta l_{j}\right)+\beta E\left[V\left(\mathbf{s}^{\prime} \mid \mathbf{s}\right)\right]
\end{aligned}
$$

The ex-ante value function for an incumbent is a combination of the payoffs if the firm stays or exits:

$$
V_{j}(\mathbf{s})=\int \pi_{j}(\mathbf{s}) d S+\left(1-p^{x}\left(s_{j}\right)\right) V_{j}^{\text {stay }}(\mathbf{s})+p^{x}\left(s_{j}\right) f_{j}^{x}
$$

In $(13), p^{x}\left(s_{j}\right)$ is the probability that firm $j$ exits the market. It is given by

$$
\begin{aligned}
p^{x}\left(s_{j}\right) & =\operatorname{Pr}\left(f_{j}^{x}>V_{j}^{\text {stay }}(\mathbf{s})\right) \\
& =1-F^{x}\left(V_{j}^{\text {stay }}(\mathbf{s}) ; \gamma^{x}\right) .
\end{aligned}
$$

The continuation value, $V_{j}^{\text {stay }}(\mathbf{s})$, can be obtained by inverting equation (14), $V_{j}^{\text {stay }}(\mathbf{s})=\left(F^{x}\right)^{-1}\left(1-p^{x}(s) ; \gamma^{x}\right)$. The expected sell-off value, $\tilde{f}_{j}^{x}$, conditional on exit is $E\left[f_{j}^{x} \mid f_{j}^{x}>\left(F^{x}\right)^{-1}\left(1-p^{x}(\mathbf{s}) ; \gamma^{x}\right)\right]$, i.e., it is a function of the probability of exit and the parameters of the exit distribution, $\gamma^{x}$. The recovered values $\tilde{\theta}_{0}^{i,+}$, $\tilde{\theta}_{0}^{i,-}, \tilde{\theta}_{0}^{l,+}, \tilde{\theta}_{0}^{l,-}$, and $\tilde{f}_{j}^{x}$ are the means of the distributions $F^{i,+}, F^{i,-}, F^{l,+}, F^{l,-}$, 
and $F^{x}$ only when firms receive favorable draws. To avoid this problem, the fixed costs can be recovered using linear sieve (Ryan, 2012):

$$
\begin{array}{ll}
\tilde{\theta}_{0}^{i,+}\left(p_{j}^{i,+}\right)=\boldsymbol{\delta}^{i,+} \boldsymbol{b} \boldsymbol{s}\left(p_{j}^{i,+}(s)\right), & \tilde{\theta}_{0}^{i,-}\left(p_{j}^{i,-}\right)=\boldsymbol{\delta}^{i,-} \boldsymbol{b} \boldsymbol{s}\left(p_{j}^{i,-}(s)\right), \\
\tilde{\theta}_{0}^{l,+}\left(p_{j}^{l,+}\right)=\boldsymbol{\delta}^{l,+} \boldsymbol{b} \boldsymbol{s}\left(p_{j}^{l,+}(s)\right), & \tilde{\theta}_{0}^{l,-}\left(p_{j}^{l,-}\right)=\boldsymbol{\delta}^{l,-} \boldsymbol{b} \boldsymbol{s}\left(p_{j}^{l,-}(s)\right), \\
\tilde{f}_{j}^{x}\left(p_{j}^{x}\right)=\boldsymbol{\delta}^{x} \boldsymbol{b} \boldsymbol{s}\left(p_{j}^{x}(s)\right), &
\end{array}
$$

where $\boldsymbol{\delta}$ parameters are finite and $\mathbf{b s}(\cdot)$ are basis functions defined from the probability of positive investment, $p^{i,+}$; the probability of negative investment, $p^{i,-}$; the probability of positive labor adjustment, $p^{l,+}$; the probability of negative labor adjustment, $p^{l,-}$; and the probability of exit, $p^{x}{ }^{34}$ The distribution of sunk entrycosts can be recovered by matching its cumulative distribution to the predicted probability of entry. A firm enters when the value of doing so, $E V^{e}(s)$, is larger than $f_{j}^{e}$. By simulating many forward paths of possible outcomes given that the firm entered, and averaging over those paths, I obtain the expected value of entry, which I then match against observed rates of entry. Therefore, the probability that a firm enters is given by

$$
\operatorname{Pr}\left(f_{j}^{e} \leq E V_{j}^{e}(s)\right)=F^{e}\left(E V^{e}(s) ; \gamma^{e}\right)
$$

where $F^{e}\left(\cdot ; \gamma^{e}\right)$ is the cumulative distribution of sunk entry-costs. The entry probability, estimated by logit, gives $\operatorname{Pr}($ entry $\mid s)$. If $n s$ is the number of simulated states from which $E V^{e}$ is recovered, then the parameters of the distribution are estimated from the following optimization problem:

$$
\min _{\gamma^{e}} \frac{1}{n s} \sum_{k}^{n s}\left[\operatorname{Pr}(\text { entry } \mid s)-F^{e}\left(E V^{e}(\boldsymbol{s}) ; \gamma^{e}\right)\right]^{2} \text {. }
$$

\footnotetext{
${ }^{34}$ If there is a trade-off between positive and negative investment, then both probabilities might appear in the setup cost functions. However, this increases the number of the parameters to be estimated.
} 
The paper uses logit approximation to estimate entry and exit probabilities. ${ }^{35}$ To be more precise, I estimate the following entry and exit policies for all states:

$$
\begin{aligned}
\operatorname{Pr}(\text { entry } \mid \mathbf{s})= & \phi\left(\alpha_{0}+\alpha_{1} \sum_{h \neq j} \omega_{j m t}\right. \\
& +\alpha_{2} k_{j m t}+\alpha_{3} \sum_{h \neq j} k_{h m t}+\alpha_{4} \text { firms }_{m t}+\alpha_{5} \text { after }_{2000} \\
& \left.+\alpha_{6} \text { foreign }_{j m t}+\alpha_{7} \text { medium }_{j m t}+\alpha_{8} \text { large }_{j m t}+\boldsymbol{\alpha}_{m}\right) \\
\operatorname{Pr}(\text { exit } \mid \mathbf{s})= & \phi\left(\alpha_{0}+\alpha_{1} \omega_{j m t}+\alpha_{2} \sum_{h \neq j} \omega_{j m t}\right. \\
& +\alpha_{3} k_{j m t}+\alpha_{4} \sum_{h \neq j} k_{h m t}+\alpha_{5} \text { firms }_{m t}+\alpha_{6} \text { after }_{2000} \\
& \left.+\alpha_{7} \text { foreign }_{j m t}+\alpha_{8} \text { medium }_{j m t}+\alpha_{9} \text { large }_{j m t}+\boldsymbol{\alpha}_{m}\right) .
\end{aligned}
$$

Both policy functions contain a dummy variable for before and after the dot-com bust.

Estimating structural parameters. The evolution process of the state vector and the level of payoff associated with each state are described by the first step estimation of productivity, policy functions, and evolution of demographic characteristics. In the second step of the estimation, I recover the rest of the parameters of cost functions by finding the set of parameters that make the firm's policy function optimal. Having the estimates from the first stage, I simulate the evolution of the market under various conditions. This is possible because the first stage estimates characterize what each firm would do in all possible situations. Using forward simulation, I find parameters of the optimal policy function that minimize the profitable deviations from these observed strategies.

Firm behavior is simulated under two alternative strategies in order to identify the investment cost parameters. The first scenario implies that all firms use the optimal strategies recovered in the first stage; this strategy is denoted $\boldsymbol{\sigma}(\mathbf{s})$. The second scenario implies that a single firm deviates from the optimal strategy while

\footnotetext{
${ }^{35}$ In many cases, entry and exit strategies take the form of simple cutoff rules in dynamic oligopoly models.
} 
all other firms use the optimal strategies. The strategy profile $\boldsymbol{\sigma}(\mathbf{s})$ is an MPNE if and only if

$$
V_{j}\left(\mathbf{s}, \sigma_{j}(\mathbf{s}), \boldsymbol{\sigma}_{-j}(\mathbf{s}) ; \boldsymbol{\theta}\right) \geq V_{j}\left(\mathbf{s}, \sigma_{j}^{\prime}(\mathbf{s}), \boldsymbol{\sigma}_{-j}(s) ; \boldsymbol{\theta}\right)
$$

for all states $\mathbf{s}$, all firms $j$, and alternative profiles $\sigma_{j}^{\prime}(\mathbf{s})$. The minimum distance estimator is constructed using this set of inequalities. Due to the linearity in the cost functions, the optimality conditions (17) can be re-written as $\left[W_{j}\left(\mathbf{s}, \sigma_{j}(\mathbf{s}), \boldsymbol{\sigma}_{-j}(\mathbf{s}) ; \boldsymbol{\theta}, \boldsymbol{\alpha}\right)-W_{j}\left(\mathbf{s}, \sigma_{j}^{\prime}(\mathbf{s}), \boldsymbol{\sigma}_{-j}(\mathbf{s}) ; \boldsymbol{\theta}\right), \boldsymbol{\alpha}\right] \boldsymbol{\theta} \geq 0$. The above equation can be written in terms of profitable deviations from the optimal policy

$$
g(x ; \boldsymbol{\theta}, \boldsymbol{\alpha})=\left[W_{j}\left(\mathbf{s}, \sigma_{j}(\mathbf{s}), \boldsymbol{\sigma}_{-j}(s) ; \boldsymbol{\theta}, \boldsymbol{\alpha}\right)-W_{j}\left(\mathbf{s}, \sigma_{j}^{\prime}(\mathbf{s}), \boldsymbol{\sigma}_{-j}(s) ; \boldsymbol{\theta}, \boldsymbol{\alpha}\right)\right] \boldsymbol{\theta},
$$

where $\alpha$ represents the parametrization of the policy functions. More specifically, alternative policies are drawn from a distribution $F$ of all policies to generate a set of inequalities indexed by $x$. The estimates of $W_{j}$, denoted $\tilde{W}_{j}$, are obtained using forward simulation. They are used in the sample analog of the objective function

$$
Q_{n}(\boldsymbol{\theta}, \boldsymbol{\alpha})=\frac{1}{n_{I}} \sum_{k=1}^{n_{I}}(\min \{\tilde{g}(x, \boldsymbol{\theta}, \boldsymbol{\alpha}), 0\})^{2} .
$$

I use the Nelder-Mead method to obtain the starting values. Then I plug the estimated parameters as started values in the Uncmin optimization routine. ${ }^{36}$ Another alternative is to use the Laplace-type estimator (Chernozhukov and Hong, 2003). The present paper estimates the distribution of entry costs using a procedure that matches the observed entry rates to the simulated values of entering at each state. Alternative estimators. Another estimator that can be used is simulated moments estimator, which is a class of generalized method of moments (GMM) estimators (Hansen, 1982; Pakes and Pollard, 1989). This estimator minimizes the

\footnotetext{
${ }^{36}$ Uncmin performs unconstrained nonlinear optimizations (http://www1.fpl.fs.fed.us/optimization.html).
} 
distance between a set of unconditional moments from the data and the simulated counterparts from the model (Gallant and Tauchen, 1996; Hall and Rust, 2003). The advantage of this estimator is that we do not need to simulate alternative policies. It only requires to choose informative moments to match for identification of the structural parameters. ${ }^{37}$

Standard errors. The first stage errors affect the standard errors in the second stage. The Uncmin optimization method gives the final estimates and the reported standard errors. Because of forward simulations, there is a computation burden to correct the second stage standard errors, i.e., the reported standard errors are downward biased. However, recent econometric literature suggests potentially easy computation alternatives to consider. Ackerberg et al. (2012) propose a numerical equivalence between asymptotic variance for two-step semiparametric estimators when the sieves method is used in the first stage. Applying this approximation, the results indicate no significant differences in the estimated standard errors.

\section{Results}

This section presents the results of estimates of productivity, revenue-generating function, and optimal firm policies, i.e., in terms of entry, exit, investment in technology, and labor. The estimates of cost parameters are discussed in the second part of this section.

Before I discuss the estimated productivity results, I would like to summarize the results regarding labor productivity and capital intensity. Figures 3 and 4 present the evolution of the labor productivity distribution and capital intensity for the three IT services sectors. Labor productivity is measured as value added

\footnotetext{
${ }^{37}$ Goettler and Gordon (2012) use this estimator in their study on microprocessor industry.
} 
per number of employees. The firms in software and operational services with low labor productive (10th percentile) experienced a decrease in labor productivity in 2000, but then started to recover in 2001. The peak of median labor productivity occurred in 1999 for software and operational services and in 2000 for maintenance. While the labor productivity of median software and operational firms shows a weak but positive trend, the median maintenance firms had a negative trend after 2000. The highly labor-productive firms (90th percentile) increased their labor productivity from 1997 and 2000 (software and maintenance), but then those in software stagnated and remained fairly constant and those in operational services actually went down. The labor productivity dispersion decreased in all sectors after 2000 (particularly quickly in operational services). To avoid possible outliers, I measure productivity dispersion as the interquartile range over median. Software and operational services sectors have larger labor productivity dispersion than does the maintenance sector.

The next step is to look into capital intensity. Median firms and firms in the 90th percentile of capital intensity had an upward trend in all three sectors, but those at the 10th percentile decreased only in the maintenance sector after 2000 (Figure 4). ${ }^{38}$ The capital intensity dispersion increased for maintenance and for software (small slope of the trend). For operational services, the capital intensity dispersion decreased until 2001 and then started to increase.

Productivity estimates. The theoretical model assumes that productivity is the state variable that captures all important aspects of an IT firm and that there is a direct link between productivity and quality. So, I assume that IT firms that offer high quality services have high productivity. Table 5 presents the results from estimating the value-added generating function using OLS and the semiparamet-

\footnotetext{
${ }^{38}$ Using UK data, Faggio et al. (2007) find that industries with high productivity growth have a large increase in IT capital intensity.
} 
ric estimator presented in Section $4 .{ }^{39}$ Firm productivity is recovered from the estimation of the value added generating function.

By using the OLS estimator, the coefficient of labor is around 1, suggesting presence of a simultaneity problem (Marschak and Andrew, 1944). Since firms productivity is positively correlated with labor, a large labor coefficient is not a surprise. Furthermore, it is expected that firms with large capital stock (large firms) stay in the market even if they have low productivity, i.e., the coefficient of the capital is downward biased for the OLS estimator (selection bias). Furthermore, the results show that the null hypothesis of constant returns to scale is accepted using the OLS estimator.

The last two columns of Table 5 show the estimates of the value-added generating function using the extended Olley and Pakes (1996) estimator (EOP) presented in Section 4. In addition to controlling for endogeneity and selection, the main advantage of this estimator is that it to some extent controls for a price bias by introducing a simple demand function. This allows me to estimate mark-ups for the IT services. Since we expect different demand elasticities for the different IT sectors, I make separate estimations for software and for operational services and maintenance. Column 3 (Table 5) presents the estimates for the software subsector. Compared to OLS, the labor coefficient goes in the right direction using EOP, i.e., it decreases to 0.680 , and the capital coefficient increases to 0.374 . The estimated elasticity of demand for software is about -4.6, implying a mark-up of 1.277. For grouped operational services and maintenance firms (column 5), the estimated labor coefficient decreases to 0.789 and the capital coefficient increases to 0.208 compared EOP and OLS. The estimated demand elasticity is about -5.96 ,

\footnotetext{
${ }^{39}$ The results using the Ackerberg et al. (2006) estimator (ACF) are available from the author. In the ACF estimator, I control for both endogeneity and selection. The ACF estimator controls for investment in the market threshold function that affects the likelihood of exit, but does not control for prices or wages.
} 
yielding a mark-up of $1.52 .{ }^{40}$ The estimated productivity using the EOP estimator is used in the rest of the paper.

Figure 5 shows the evolution of different parts of the productivity distribution for different size classes. It does not distinguish between what IT sector the firms belong to and type of firm, e.g., an entrant, an exit, or an incumbent. The results suggest that scale matters: large firms are the most productive, followed by medium-sized and small firms. This holds for the entire productivity distribution. Low productivity firms (10th percentile) increased their productivity (small positive slope) until 2001. For the median and the high productivity firms (90th percentile), there are three distinct periods. Their productivity was rather constant from 1997 to 1999, developed positively from 1999 to 2000, but negatively starting in 2001. These periods are also important for the dispersion trend, a decrease from 1999 to 2001 for large and medium firms. Medium-sized firms show the largest decrease in productivity dispersion. Small firms have a constant productivity dispersion over time. A decrease in productivity dispersion can be interpreted as an increase in competition, i.e., firms increase their quality and become closer to each other.

Summarizing, the paper finds that the 2001 dot-com bubble bust has affected firms differently depending on productivity and size. There is a smaller difference in productivity levels among large and median low productive firms (10th percentile) than among high productive firms (90th percentile). On the other hand, the gap between small and medium-sized firms decreases in the upper part of the productivity distribution (90th percentile).

Dynamic productivity decomposition. To analyze the productivity dynamics at the industry level, the present paper uses a dynamic productivity decomposition. Olley and Pakes (1996) propose a static decomposition of aggregate

\footnotetext{
${ }^{40}$ It would have been more informative to estimate the mark-ups before and after the dot-com bust. Unfortunately, this is not possible due to data constraint.
} 
productivity where the weighted productivity for continuing stores, $\Omega_{t}$, has two components: (1) unweighted contribution of productivity improvements, $\bar{\Omega}_{t}$ and (2) market share reallocations for the continuing firms $\operatorname{cov}\left(m s_{j t}, \omega_{j t}\right) \equiv \sum_{j}\left(m s_{j t}-\right.$ $\left.\overline{m s}_{t}\right)\left(\omega_{j t}-\bar{\Omega}_{t}\right)$. The change in the productivity index from period $t$ to period $t^{\prime}$, $\Delta \Omega_{t, t^{\prime}}$, can be written as

$$
\Delta \Omega_{t, t^{\prime}}=\Delta \bar{\Omega}_{t, t^{\prime}}+\Delta \operatorname{cov}_{t, t^{\prime}}
$$

Since the OP decomposition ignores entry and exit, Melitz and Polanec (2009) (MP) suggest a dynamic OP decomposition where there is a positive contribution for entering and exiting firms only when the aggregate productivity of these firms is larger than that of continuing firms in corresponding periods. The aggregate productivity in periods $t$ and $t^{\prime}$ can be decomposed as

$$
\begin{aligned}
& \Omega_{t}=m s_{C_{t, t^{\prime}}, t} \Omega_{C_{t, t^{\prime}}, t}+m s_{X_{t, t^{\prime}}, t} \Omega_{X_{t, t^{\prime}}, t} \\
& \Omega_{t^{\prime}}=m s_{C_{t, t^{\prime}}, t^{\prime}} \Omega_{C_{t, t^{\prime}, t^{\prime}}}+m s_{E_{t, t^{\prime}, t^{\prime}} \Omega_{E_{t, t^{\prime}}, t^{\prime}}}
\end{aligned}
$$

where $m s_{C_{t, t^{\prime}}, t}, m s_{E_{t, t^{\prime}}, t^{\prime}}$, and $m s_{X_{t, t^{\prime}}, t}$ are the aggregate market shares of incumbents in period $t$, of entrants in period $t^{\prime}$, and of exits firms in period $t$, respectively. Thus, the change in aggregate productivity can be written as

$$
\Delta \Omega_{t, t^{\prime}}=\Delta \bar{\Omega}_{C_{t, t^{\prime}}}+\Delta \operatorname{cov}_{C_{t, t^{\prime}}}+m s_{E_{t, t^{\prime}}, t^{\prime}}\left(\Omega_{E_{t, t^{\prime}}, t^{\prime}}-\Omega_{C_{t, t^{\prime}}, t^{\prime}}\right)+m s_{X_{t, t^{\prime}}, t}\left(\Omega_{C_{t, t^{\prime}}, t}-\Omega_{X_{t, t^{\prime}}, t}\right) .
$$

Table 6 presents the MP productivity decomposition from 1997 to 2002 for the software and operational services sub-sectors using 1997 as the base year. For software, the productivity growth is around 21 percent from 1997 to 2000 but only 6 percent from 1997 to 2002. The largest growth occurred from 1997 to 2001 (23 percent). Entrants contributed negatively to productivity growth, i.e., entrants 
were less productive than continuing firms. On the other hand, the exit firms contributed positively to productivity growth, and the contribution increased over time, e.g., from 5 percent in 1997 to around 18 percent in 2001. From 1997 to 2001, the continuing software contributed the most to growth: 35 percent (1997-2000) and 45 percent (1997-2001). From 1997 to 2002, the software firms that exited contributed more to productivity growth than did continuing firms (12 percent versus 7.5 percent).

For operational services and maintenance, the productivity growth was about 70 percent from 1997 to 2000 and about 32 percent from 1997 to 2002 . Continuing firms accounted for almost all productivity growth from 1997 to 2000. Yet, exit firms contributed the most (50 percent) to productivity growth from 1997 to 2002.

Summarizing, the decomposition results emphasize the importance of net exit for productivity growth in the IT services after the 2001 dot-com bust. This suggests important changes in the market dynamics after the impact of aggregate shocks in the market, e.g., less productive firms exit.

Payoff generating function. The estimated productivity is used to obtain a payoff generating function $(r(\cdot))$, needed to evaluate the value functions, for each subsector. I do not have additional information to model the intermediate inputs cost. Using value-added to proxy for $r(\cdot)$ might imply overreporting since I model both labor and investment costs. To avoid this problem, I report the estimates of the payoff generating function using revenues. However, there is a high correlation (about 0.7 ) between value-added and revenues in my sample. Table 7 presents two specifications. The first is a simple linear regression estimated by OLS. A flexible way to model firms' revenues as a function of the state variables is to use the method of linear sieves, i.e., a simple semi-nonparametric approach to estimate unknown functions. The second specification uses a non-parametric cubic b-splines approximation and is estimated by the OLS estimator. A nice 
feature of the linear sieves is their simple analytical form. This paper uses cubic b-splines as basis functions, denoted $b s(\cdot)$, which are finite dimensional piecewise polynomials (Appendix C provides a short description of the cubic b-splines).

The revenues are a function of firms' productivity, rivals' productivity, own capital, rivals' capital, number of non-IT firms in the local market, firm size (medium or large), and type of ownership (domestic or foreign). The variables are in log form. Rivals' productivity captures the effect of the competitive pressure on firms' revenues. The impact of rival size on revenues is captured by rivals' capital, which to some extent also captures competition, i.e., the number of IT firms. At the local market, number of non-IT firms measures demand for IT services. ${ }^{41}$

The OLS results (Panel A) show that doubling productivity increases revenues about 58 percent for software, and 53 percent for operational services and for maintenance and repair. Doubling the capital stock increases revenues by about 37 percent for software, 29 percent for operational services, and 33 percent for maintenance and repair firms. If the number of non-IT firms at the local market level doubles, then revenues go up about 12 percent for software, 33 percent for operational services, and 22 percent for maintenance and repair firms. Rivals' productivity and capital have a negative impact on software and operational firms' sales. For software and operational services, foreign IT firms have revenues about 19 percent higher than domestic IT firms. The dot-com bubble bust decreases revenues by about 20 percent for software and operational services and by 34 percent for maintenance and repair.

Panel B (Table 7) presents only a summary of the estimation results using b-splines with 6, 9, and 14 knots. For software and operational services, the adjusted $R^{2}$ increases, the root of mean squared errors (RMSE) and absolute mean errors (MAE) decrease using b-splines as basis functions for firms' own productiv-

\footnotetext{
${ }^{41}$ There is a high correlation (0.99) between number of firms and population at the county level.
} 
ity, firms' own capital, rivals' productivity, and rivals' capital. This suggests that there is no need to use nonlinear approximation for operational services' revenues. Even if the simple linear regression does a good job estimating revenues, there is a significant increase in adjusted $R^{2}$, about 13 percentage points, and the RMSE decreases from 0.622 (OLS) to 0.599 when cubic b-splines are used for the software industry, for example. In the forward simulations, b-spline specification with 14 knots is used to estimate the value functions for software and operational services. Policy functions. The next step is to estimate investment and labor policy functions for all firms. In addition, I estimate the entry and exit policies. All these policies are estimated for each IT sub-sector. Table 8 presents the logit estimates for the exit (Panel A) and entry (Panel B) policies. In my dataset, entry and exit are based on organization number.

For all sub-sectors, high productivity firms and firms located in markets with a large number of firms (only software and operational services) are less likely to exit. In all sub-sectors, firms are also more likely to exit after the 2001 dot-com bust. For software and operational services, firms are less likely to exit in markets where rivals have large capital stocks and high productivity. In the Swedish case, large firms are located in large markets and might have subsidiary (technology and innovation clusters). However, markets with large capital stocks imply high demand, i.e., there is still room to differentiate in these sub-sectors. For software and operational services, I find that firms with large capital are more likely to exit. There have been many technological innovations in this industry in recent years. Failing to update utilized technology has a negative impact on firm performance. Acquisitions were made during the studied period. This may explain the findings that software and operational service firms are more likely to exit if the firm has over 20 employees.

My findings indicate that IT firms are more likely to enter if rivals have high 
productivity, i.e., if there is sufficient demand. Software firms are less likely to enter markets where rivals have extensive capital, i.e., markets with large firms, but more likely to enter markets with a large number of firms. Hence, these markets offer sufficient demand and skilled labor. It is less likely to have foreign entrants (software and operational services) and to observe entry after the dot-com bust.

Table 9 shows the investment policy function estimates for all IT firms by subsector. Panel A presents the estimates from a simple linear investment specification. Panel B shows summary results from non-parametric regressions using cubic b-splines as basis functions for linear sieves approximations of unknown functions in own productivity, rivals' productivity, and rivals' capital. Both regression specifications use the OLS estimator. For software and operational services, productivity has a positive and significant effect on investment, i.e., firms with high productivity invest more in capital. For maintenance and repair, firms invest more if rivals reduce their capacity. For all IT sub-sectors, firms with large capital stock invest more, but they invest less after 2000. For software and operational services, increasing the business opportunities, i.e., increasing the number of non-IT firms, has a positive impact on investment. Allowing the marginal effects to depend on the size of the variables (b-splines specifications), the accuracy of recovering the observed investment increases. By using the non-parametric specification, the adjusted $R^{2}$ increases from 17 to over 86 percent for software, from 37 to 85 percent for operational services, and from 58 to 95 percent for maintenance and repair. Allowing for non-linearities in productivity and capital reduces the RMSE at least two times, and the correlation between observed and predicted investment increases from 0.41 to 0.93 for software, from 0.61 to 0.93 for operational services, and from 0.77 to 0.98 for maintenance and repair firms.

Table 10 presents the labor policy function results for all IT firms. A linear specification does a good job fitting the observed number of employees. For all IT 
sectors, the adjusted $R^{2}$ is about 90 percent. Allowing for non-linearities gives a better fit only for software and maintenance and repair labor policies. ${ }^{42}$

By doubling their productivity, the number of employees increases by about 52 percent for software and by about 48 percent for operational services and maintenance and repair firms. A double capital stock increases the number of employees about by 27 percent for software, by 20 percent for operational services, and by about 15 percent for maintenance and repair. If the number of firms doubles (double potential demand), operational services firms increase labor by about 33 percent and maintenance and repair firms by about 50 percent. On average, foreign firms have about 10 percent more employees than domestic ones in software. The corresponding numbers for operational services and maintenance and repair are around 8 percent and 37 percent, respectively. After the dot-com bust, IT firms reduced the number of employees by about 28 percent in software, by 24 percent in operational services, and by about 22 percent in maintenance and repair.

Estimation of structural parameters. In the second step, I obtain the cost parameters for each IT sub-sector before and after the IT dot-com bust. First, the value functions are estimated using the policy functions estimated in the previous subsection. The value functions are the expectations of discounted profits over current and future states, and profit shocks. In the estimation, 100 forward simulations are used and the discount parameter, $\beta$, is fixed to 0.95 . For policy functions, the cubic b-spline estimates are used to extend the panel (forward simulations).

Since I control for local market competition, the order of generating the policy functions is very important. First, future productivity and capital stock are generated for each firm and year. To generate future productivity previous investment

\footnotetext{
${ }^{42} \mathrm{~A}$ negative adjusted $R^{2}$ obtained for operational services regressions suggests that there is no need for non-linearities.
} 
is also added as variable in the $g(\cdot)$ function. Second, the rivals' productivity and capital are computed for each market and year. Third, the revenues and required labor are generated knowing that the population and the number of other firms evolve as exogenous processes. Fourth, the exit estimates are used to simulate whether firms exit or continue. If a firm continues, the investment and setup cost components for investment and labor are generated using cubic b-splines with 14 knots. The setup cost components are the basis cubic b-splines in the estimated probability to invest, dis-invest, hire, or fire. The high setup costs might cause the observed lumpy investment and lack of adjustment in employment, i.e. the dynamics of investment and labor, to depend on the setup costs. Hamermesh (1989) finds empirical evidence that the adjustment labor costs, which are independent of the level changes, are determinants of lumpy adjustment. ${ }^{43}$ I assume that employment dynamics in IT are generated by a process that distinguishes between hiring and firing costs. ${ }^{44}$

Table 11 shows the estimated cost parameters for each sub-sector before (19972000) and after (2001-2002) the 2001 dot-com bust. Panel A presents the estimated results for investment. The quadratic cost of adjustment implies that the future value of additional capital depends on the choice with respect to adjustment. I present only the results for positive investment. After 2003, IT firms started to invest again (Section 2). Therefore, to be close to how industry behave I use the investment policy function from 1996-2000 in the forward simulation after 2003. Since capital stock is a state variable, allowing for excessive negative investment makes smaller firms have a short life. For this reason, the results for negative investment are not significant. This paper finds that setup investment costs are

\footnotetext{
${ }^{43}$ Hamermesh and Pfann (1996) find evidence of asymmetric adjustment costs, e.g., the cost of advertising might be proportional to the number of hired employees but not firing cost (Pfann and Palm, 1993). Since the asymmetry implies non-linearity in the shape of the cost function, it would be impossible to estimate the cost parameters without additional approximations to reach linearity.

${ }^{44}$ In my case, I observe the number of employees in November.
} 
higher for software but lower for operational services and maintenance after the dot-com bust. In the IT services case, the setup investment cost is associated with system and network configuration costs when firms change technology. Operational service firms have at least twice the setup costs of software and maintenance and repair. This sub-sector includes data processing and database activities, which require large costs in case of migration from one system to another even if the machines get cheaper due to technological innovations. However, the implied distribution of investment costs indicates higher investment costs, on average, for operational services after the dot-com bust even if the setup costs are lower (Panel B). During the study period, there was significant innovation with respect to on both hardware and software in the database management area, e.g., integration of Oracle (commercial product) and MySQL (free) on Linux. Fast access to information became very important at the same time as the complexity of the information stored increased. Therefore, firms had to invest in advanced technologies, which might explain the larger cost after the dot-com bust in this sub-sector. This contrasts the maintenance and repair sub-sector, where investment costs decreased after dot-com. Since advances in technology make hardware cheaper, firms prefer to buy rather than repair.

Panel $\mathrm{C}$ shows the estimates for labor adjustment costs. For software, the setup costs of positive labor adjustment are about 4 times larger after the dot-com bust. The variable marginal labor adjustment cost is about SEK 322,000 before and about SEK 271,000 after the dot-com bubble. The findings of larger setup costs and smaller variable adjustment labor costs after the dot-com bust suggest that firms face uncertainties regarding demand and might rather work with external consultants than hire new staff. The firing setup costs (about SEK 366,000) are about 2 times larger after the dot-com bust.

For operational services, the results indicate larger setup costs for positive la- 
bor adjustment before the dot-com bust. However, the setup costs are larger for negative than for positive adjustment. Here, setup labor costs might also include expenses in connection with employees' training, e.g., training to become a certified expert. This might explain the decrease in labor adjustment setup costs after the dot-com bust, when the firms were focused on reducing the costs due to the aggregate decrease in demand. Operational services has larger marginal cost of adjustment after the dot-com bust, i.e., about SEK 379,000 before and SEK 432,708 after. The marginal labor adjustment costs are larger for operational services than for software firms.

For maintenance and repair, the estimates indicate about the same positive labor adjustment setup cost (SEK 400,000) before and after the dot-com bust. Furthermore, the marginal cost of positive labor adjustment is with about SEK 50,000 less (SEK 245,000). The parameters for the negative adjustment costs could not be identified due to too few observations.

Having the estimated labor parameters, the implied distributions of cost for labor adjustment can be computed (Panel D). The 2001 dot-com bust implies higher positive labor adjustment costs for software but lower positive labor adjustment cost for operational services and maintenance and repair.

Distributions of exit and entry sunk costs. A median firm that exits has one employee for software and two employees for operational services and maintenance and repair. After the burst of the dot-com bubble, firms in software and operational services have higher (sell-off) while the maintenance and repair firms have lower scrap values (Table 11, Panel E).

To estimate entry cost, I assume that it follows a normal distribution. Using the minimum distance estimator, I recover mean and standard deviation for each industry before and after the dot-com bust. A median entrant in software or operational services has two employees, and a median entrant in maintenance 
and repair has three. The mean entry cost for software and operational services is estimated to be about SEK 19,000 and SEK 120,000, respectively. However, I find no significant difference between entry costs before and after the dot-com bust for software and operational services, i.e., demand uncertainty and large setup costs might explain the decrease in the number of entrants and their size. For maintenance and repair, the mean entry cost (about SEK 135,000) is not significant. One possible explanation to this is that this industry had few entrants. The low value of sunk entry costs for software firms - about 6 times lower than for operational services - explains the observed differences in the number of entrants; i.e., the yearly number of entrants in software was about 8 times the number of entrants in operational services.

\section{Conclusions}

This paper analyzes the impact of the 2001 dot-com bust on productivity and cost structure in the Swedish IT services. To understand the differences in productivity among the IT service sub-sectors and how the firms change their behavior when facing demand shocks, the paper analyzes the possible changes in cost structure caused by the burst of the 2001 dot-com bubble. Since changes in the cost structure impact the market dynamics and therefore productivity growth, they are important both for market structure and agencies that support this industry, which is dominated by small firms (number of firms).

The findings indicate that differences between setup (fixed) and variable costs help explain observed behavior in investment and labor policies in the IT services industry. Since the relative importance of setup and variable adjustment costs can not be measured directly from the observed data, they are inferred from the 
model. The results indicate higher fixed investment and labor adjustment costs for software. The fixed costs are lower for operational services after the dot-com bust. The downturn in productivity growth after the dot-com bubble can be explained not only by reduced demand but also by large adjustment costs.

The results show that from 1997 to 2002, the productivity growth was about 6 percent for software and about 32 percent for operational services. After the dot-com bust, net exit contributed the most to productivity growth, suggesting important changes in the market dynamics after this aggregate shock.

Entrants are less productive than incumbent IT firms. Software firms invest more if there is an increase in business opportunities at the local market level. On average for the IT sub-sectors, firms with large capital stocks invest more. Yet, they invested less after the 2001 dot-com bust. This study finds that, among the low productivity IT firms, medium and large firms were affected the most by the dot-com bust.

Changes in cost structure cause changes in prices (and vice-versa), but this important aspect is not explicitly modeled here due to difficulties finding price data for IT services. Even if the paper controls for unobserved prices in an indirect way, there is still possible to have correlated unobserved demand shocks in estimated productivity (Ackerberg et al., 2008; De Loecker, 2011; Foster et al., 2008). A detailed investigation of demand and a better understanding of the entry process would be interesting for future research. 


\section{References}

Ackerberg, D., Benkard, L., Berry, S., Pakes, A., 2008. Handbook of Econometrics,. Vol. 6. Elsevier, Ch. Econometric Tools for Analyzing Market Outcomes, pp. $4171-4276$.

Ackerberg, D., Caves, K., Fraser, G., 2006. Structural identification of production functions, Mimeo, UCLA.

Ackerberg, D. A., Chen, X., Hahn, J., 2012. A practical asymptotic variance estimator for two-step semiparametric estimators. The Review of Economics and Statistics 94 (2), 481-498.

Aghion, P., Blundell, R., Griffith, R., Howitt, P., Prantl, S., 2009. The effects of entry on incumbent innovation and productivity. Review of Economics and Statistics 91 (1), 20-32.

Aguirregabiria, V., Mira, P., 2007. Sequential estimation of dynamic discrete games. Econometrica 75 (1), 1-53.

Ai, C., Chen, X., 2003. Efficient estimation of models with conditional moment restrictions containing unknown functions. Econometrica 71 (6), 1795-1843.

Aw, B. Y., Chung, S., Roberts, M. J., 2003. Productivity, output, and failure: A comparison of Taiwanese and Korean manufacturers. Economic Journal 113 (491), 485-510.

Bajari, P., Benkard, L., Levin, J., 2007. Estimating dynamic models of imperfect competition. Econometrica 75 (5), 1331-1370.

Bartelsman, E., Doms, M., 2000. Understanding productivity: Lessons from longitudinal microdata. Journal of Economic Literature 38 (3), 569-594.

Benkard, C., 2004. A dynamic analysis of the market for widebodied commercial aircraft. Review of Economic Studies 71, 581-611.

Beresteanu, A., Ellickson, P., 2006. The dynamics of retail oligopoly, Mimeo, Duke University.

Berry, S., 1994. Estimating discrete-choice models of product differentiation. The RAND Journal of Economics 25 (2), 242-262.

Berry, S., Levinsohn, J., Pakes, A., 1995. Automobile prices in market equilibrium. Econometrica 63 (4), 841-890.

Bloom, N., Sadun, R., Van Reenen, J., 2012. Americans do I.T. better: US multinationals and the productivity miracle. American Economic Review 102 (1), $167-201$. 
Boone, J., 2000. Competitive pressure: The effects on investments in product and process innovation. RAND Journal of Economics 31 (3), 549-569.

Bower, R., 1973. Market changes in the computer services industry. Bell Journal of Economics and Management Science 4 (2), 539-590.

Cerda, M., Glanzelius, M., 2003. Service price index for computer services. industry description for SE-SIC 92 group 72 TPI project report no.2. Tech. rep., Statistics Sweden.

Chen, X., 2007. Large sample sieve estimation of semi-nonparametric models. In: Heckman, J., Leaner, E. (Eds.), The Handbook of Econometrics. Vol. 6.

Chernozhukov, V., Hong, H., 2003. A MCMC approach to classical estimation. Journal of Econometrics 115 (2), 293-346.

Coppejans, M., 2004. On Kolmogorov's representation of functions of several variables by functions of one variable. Journal of Econometrics 123, 1-31.

de Boor, C., 1978. A Practical Guide to Splines. Springer, Berlin.

De Loecker, J., 2011. Product differentiation, multi-product firms and estimating the impact of trade liberalization on productivity. Econometrica 79, 1407-1451.

Doraszelski, U., Jaumandreu, J., 2009. R\&D and productivity: Estimating production functions when productivity is endogenous, Mimeo, Harvard University.

Doraszelski, U., Satterthwaite, M., 2010. Computable Markov-perfect industry dynamics. Rand Journal of Economics 41 (2), 215-243.

Dunne, T., Klimek, S., Roberts, M., Xu, Y., 2009. Entry and exit, and the determinants of market structure. NBER Working Paper Series 15313.

Ericson, R., Pakes, A., 1995. Markov-perfect industry dynamics: A framework for empirical work. Review of Economic Studies 62, 53-83.

EU ICT Task Force Report, 2006. Fostering the competitiveness of Europe's ICT industry. Tech. rep., European Commission.

Eubank, R. L., 1988. Spline Smoothing and Nonparametric Regression. Markel Kedder, New York.

Faggio, G., Salvanes, G., Van Reenen, J., 2007. The evolution of inequality in productivity and wages. NBER Working Paper Series 13351.

Foster, L., Haltiwanger, J., Syverson, C., 2008. Reallocation, firm turnover, and efficiency: Selection on productivity or profitability? American Economic Review 98 (1), 394-425. 
Gallant, R., Tauchen, G., 1996. Which moments to match? Econometric Theory $12,657-681$.

Goettler, R. L., Gordon, B. R., 2012. Does AMD spur Intel to innovate more? Journal of Political Economy 119 (6), 1141-1200.

Gowrisankaran, G., Lucarelli, C., Schmidt-Dengler, P., Town, R., 2010. Government policy and the dynamics of market structure: Evidence from critical access hospitals, Mimeo, London School of Economics.

Hall, G., Rust, J., 2003. Simulated minimum distance estimation of a model of optimal commodity price speculation with endogenously sampled prices, Mimeo, Yale University.

Hamermesh, D. A., 1989. Labor demand and the structure of adjustment costs. American Economic Review 79, 674-689.

Hamermesh, D. A., Pfann, G. A., 1996. Adjustment costs in factor demand. Journal of Economic Literature 34, 1264-1292.

Hansen, L., 1982. Large sample properties of generalized method of moments estimators. Econometrica 50, 1929-1954.

Hotz, V., Miller, R., 1993. Conditional choice probabilities and the estimation of dynamic models. Review of Economic Studies 60 (3), 497-529.

Hulten, C., Wykoff, F., 1981. Ch. The Measurement of Economic Depreciation, in C. Hulten (ed.), Depreciation, Inflation, and Taxation of Income from Capital, Urban Institute Press, Washington, D.C.

Jones, C., Bonsignour, O., 2011. The Economics of Software Quality. AddisonWesley Professional.

Jorgenson, D. W., Ho, M. S., Stiroh, K. J., 2005. Information Technology and the American Growth Resurgence. Cambridge: MIT Press.

Jorgenson, D. W., Ho, M. S., Stiroh, K. J., 2008. A retrospective look at the U.S. productivity growth resurgence. Journal of Economic Perspective 22, 1.

Klette, T., Griliches, Z., 1996. The inconsistency of common scale estimators when output prices are unobserved and endogenous. Journal of Applied Econometrics 11 (4), 343-361.

Kretschmer, T., Miravete, E., Pernias, J., 2012. Competitive pressure and the adoption of complementary. American Economic Review 102 (4), 1540-1570.

Lerner, J., Schankerman, M., 2010. The Comingled Code: Open Source and Economic Development. The MIT Press Cambridge, Massachusetts. 
Levinsohn, J., Melitz, M., 2006. Productivity in a differentiated products market equilibrium, Mimeo, Harvard University.

Levinsohn, J., Petrin, A., 2003. Estimating production functions using inputs to control for unobservables. Review of Economic Studies 70 (2), 317-341.

Lundmark, M., 1995. Computer services in Sweden: Markets, labor qualifications ands patterns of location. Geografiska Annaler. Series B, Human Georgaphy 77 (2), 125-139.

Maican, F., 2010. Productivity dynamics, R\&D, and competitive pressure, Mimeo, University of Gothenburg.

Maican, F., Orth, M., 2009. Productivity dynamics and the role of "big-box" entrants in retailing. Working Paper 328, University of Gothenburg.

Marschak, J., Andrew, W. H., 1944. Random simultaneous equations and the theory of production. Econometrica 12 (3-4), 143-205.

Melitz, M., 2000. Estimating firm level productivity in differentiated product industries, Mimeo, Harvard University.

Melitz, M., Polanec, S., 2009. Dynamic Olley-Pakes decomposition with entry and exit, Mimeo, Princeton University.

Nevo, A., 2001. Mergers with differentiated products: The case of the ready-to-eat cereal industry. Econometrica 69 (2), 307-342.

Newey, W., Powell, J., 2003. Instrumental variables estimation of nonparametric models. Econometrica 71 (3), 1557-1569.

Newey, W., Powell, J., Vella, F., 1999. Nonparametrric estimation of triangular simultaneous equations models. Econometrica 67 (3), 565-603.

Nickell, S. J., 1996. Competition and corporate performance. Journal of Political Economy 104 (4), 724-746.

Olley, S., Pakes, A., Nov. 1996. The dynamics of productivity in the telecommunications equipment industry. Econometrica Vol. 64 (No. 6), 1263-1297.

Pakes, A., 2008. Theory and empirical work on imperfectly competitive markets. NBER Working Paper Series 14117.

Pakes, A., 2010. Alternative models for moment inequalities, Mimeo, Harvard University.

Pakes, A., Ostrovsky, M., Berry, S., 2007a. Simple estimators for the parameters of discrete dynamic games, with entry/exit examples. RAND Journal of Economics 38 (2), 373-399. 
Pakes, A., Pollard, D., 1989. Simulation and asymptotics of optimization estimators. Econometrica 57, 1027-1057.

Pakes, A., Porter, J., Ho, J., Ishii, J., 2007b. Moment inequalities and their application, Mimeo, Harvard University.

Pesendorfer, M., Schmidt-Dengler, 2003. Identification and estimation of dynamic games, mimeo, London School of Economics.

Pfann, G. A., Palm, F., 1993. Asymmetric adjustment cost in non-linear labor demand models for the Netherlands and U.K. manufacturing sectors. Review of Economic Studies 60 (2), 397-412.

Raith, M., 2003. Competition, risk, and managerial incentives. American Economic Review 93, 1425-1436.

Robinson, P., 1988. Root-n-consistent semiparametric regression. Econometrica $56(4), 931-954$.

Ryan, S., 2012. The costs of environmental regulation in a concentrated industry. Econometrica 80 (3), 1019-1062.

Ryan, S., Tucker, C., 2006. Heterogeneity and the dynamics of technology adoption, Mimeo, MIT.

Schmidt, K., 1997. Managerial incentives and product market competition. Review of Economic Studies 64, 191-213.

Schumaker, L. L., 1981. Spline Functions Basic Theory. Wiley, New York.

Sweeting, A., 2007. Dynamic product repositioning in differentiated product markets: The case of format switching in the commercial radio industry. NBER Working Paper Series 13522.

Syverson, C., 2004. Market structure and productivity: A concrete example. Journal of Political Economy 112 (2), 1181-1222.

Syverson, C., 2011. What determines productivity? Journal of Economic Literature 49 (2), 326-365.

van Ark, B., O’Mahony, M., Timmer, M. P., 2008. The productivity gap between Europe and the United States: Trends and causes. Journal of Economic Perspectives 22 (1), 25-44. 


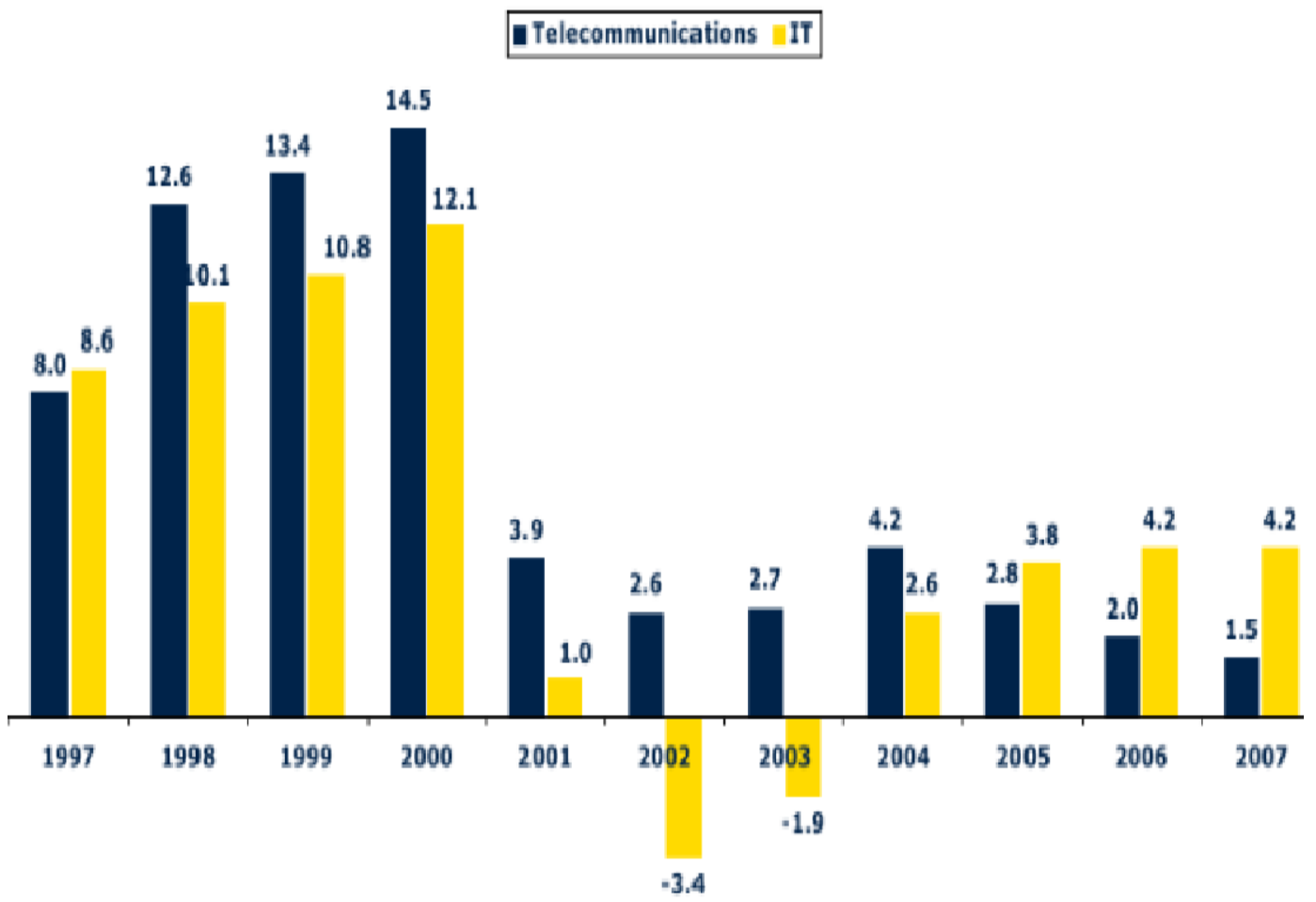

Figure 1: Western European ICT market growth, 1997-2007, in percent. Source: EITO 2006 in cooperation with IDC.

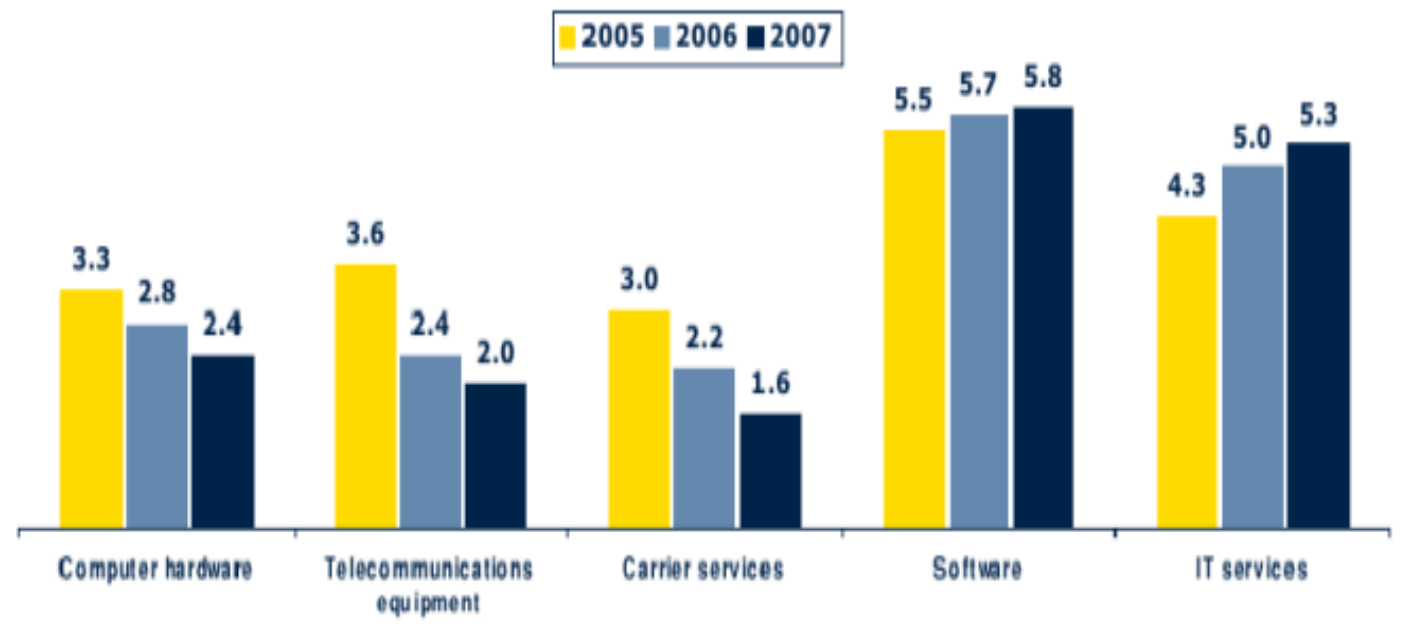

Figure 2: EU ICT, excluding Cyprus and Malta, market growth by segment, 2005-2007, in percent. Source: EITO 2006 in cooperation with IDC. 
Table 1: Characteristics of the data for the Swedish IT service industry 1996-2002

\begin{tabular}{|c|c|c|c|c|c|c|c|c|}
\hline \multicolumn{9}{|c|}{ A: All IT service firms } \\
\hline Year & Firms & Entry & Exit & Sales & $\begin{array}{l}\text { Value } \\
\text { added }\end{array}$ & $\begin{array}{c}\text { Total } \\
\text { wages }\end{array}$ & Employees & Investment \\
\hline 1996 & 4,116 & & 543 & $48,320,538$ & $21,459,073$ & $12,070,602$ & 42,686 & $1,774,708$ \\
\hline 1997 & 4,581 & 1,166 & 551 & $53,209,942$ & $25,707,591$ & $14,506,458$ & 49,883 & $2,038,902$ \\
\hline 1998 & 5,109 & 1,149 & 644 & $66,707,752$ & $31,395,570$ & $17,851,110$ & 59,208 & $2,257,806$ \\
\hline 1999 & 5,625 & 1,185 & 820 & $83,369,434$ & $38,282,741$ & $22,787,128$ & 71,133 & $3,022,545$ \\
\hline 2000 & 6,523 & 1,694 & 1,203 & $96,284,420$ & $39,710,885$ & $28,085,689$ & 85,928 & $3,668,669$ \\
\hline 2001 & 6,749 & 1,336 & 1,326 & $112,979,488$ & $48,588,640$ & $32,312,569$ & 94,096 & $3,947,814$ \\
\hline 2002 & 6,623 & 962 & & $100,931,185$ & $44,672,840$ & $29,804,633$ & 87,567 & $3,539,552$ \\
\hline \multicolumn{9}{|c|}{ B: Software } \\
\hline 1996 & 3,474 & & 445 & $35,638,817$ & $16,448,024$ & $9,376,162$ & 32,580 & $1,110,581$ \\
\hline 1997 & 3,882 & 973 & 441 & $42,341,881$ & $20,666,581$ & $11,981,723$ & 40,393 & $1,466,592$ \\
\hline 1998 & 4,398 & 1,022 & 536 & $56,348,497$ & $26,907,847$ & $15,241,528$ & 49,657 & $1,741,355$ \\
\hline 1999 & 4,908 & 1,051 & 709 & $67,495,845$ & $32,512,499$ & $19,477,029$ & 59,823 & $2,299,510$ \\
\hline 2000 & 5,742 & 1,532 & 1,017 & $76,266,817$ & $32,079,924$ & $23,499,892$ & 70,792 & $2,937,217$ \\
\hline 2001 & 6,043 & 1,222 & 1,168 & $97,738,433$ & $42,385,864$ & $28,361,781$ & 81,518 & $3,355,883$ \\
\hline 2002 & 5,932 & 856 & & $80,063,479$ & $36,335,808$ & $24,621,346$ & 71,526 & $3,007,020$ \\
\hline \multicolumn{9}{|c|}{ C: Operational services } \\
\hline 1996 & 527 & & 88 & $11,114,449$ & $4,374,038$ & $2,294,675$ & 8,580 & 646,102 \\
\hline 1997 & 583 & 174 & 100 & $9,435,368$ & $4,379,401$ & $2,139,978$ & 7,996 & 549,014 \\
\hline 1998 & 601 & 122 & 88 & $8,888,705$ & $3,781,396$ & $2,199,835$ & 7,939 & 493,259 \\
\hline 1999 & 616 & 124 & 102 & $13,227,458$ & $4,896,611$ & $2,774,268$ & 9,497 & 678,515 \\
\hline 2000 & 671 & 147 & 168 & $17,881,246$ & $6,739,992$ & $4,039,204$ & 13,299 & 709,624 \\
\hline 2001 & 602 & 101 & 141 & $12,969,458$ & $5,325,738$ & $3,305,638$ & 10,298 & 574,791 \\
\hline 2002 & 592 & 93 & & $18,956,159$ & $7,454,423$ & $4,606,482$ & 13,932 & 518,766 \\
\hline \multicolumn{9}{|c|}{ D: Maintenance and repair } \\
\hline 1996 & 115 & & 10 & $1,567,272$ & 637,011 & 399,765 & 1,526 & 18,025 \\
\hline 1997 & 116 & 19 & 10 & $1,432,693$ & 661,608 & 384,756 & 1,494 & 23,295 \\
\hline 1998 & 110 & 5 & 20 & $1,470,551$ & 706,326 & 409,747 & 1,612 & 23,191 \\
\hline 1999 & 101 & 10 & 9 & $2,646,131$ & 873,630 & 535,830 & 1,813 & 44,520 \\
\hline 2000 & 110 & 15 & 18 & $2,136,357$ & 890,968 & 546,592 & 1,837 & 21,828 \\
\hline 2001 & 104 & 13 & 17 & $2,271,597$ & 877,038 & 645,150 & 2,280 & 17,139 \\
\hline 2002 & 99 & 13 & & $1,911,548$ & 882,608 & 576,804 & 2,109 & 13,764 \\
\hline
\end{tabular}

Table 2: The 2001 dot-com bust: growth rates (percent) 2000-2001 and 2001-2002

\begin{tabular}{|c|c|c|c|c|c|c|c|c|}
\hline & \multicolumn{2}{|c|}{ Firms } & \multicolumn{2}{|c|}{ Sales } & \multicolumn{2}{|c|}{ Employees } & \multicolumn{2}{|c|}{ Investment } \\
\hline & 2000-2001 & 2001-2002 & 2000-2001 & 2001-2002 & 2000-2001 & 2001-2002 & 2000-2001 & 2001-2002 \\
\hline Software & 5 & -2 & 28 & -18 & 15 & -10 & 14 & -10 \\
\hline Operational services & -10 & -2 & -27 & 46 & -25 & 58 & -19 & -10 \\
\hline Maintenance and repair & -5 & -5 & 6 & -16 & 17 & -7 & 21 & -20 \\
\hline
\end{tabular}

NOTE: The data come from the merge between Financial Statistics(FS) and Regional Labor Statistics(RAMS)

databases. The growth rates are computed at the sub-sector level. 
Table 3: Summary statistics at the local market level for the Swedish IT service industry 1996-2002

\begin{tabular}{|c|c|c|c|c|c|}
\hline Variable & Minimun & Mean & Median & Maximum & $\begin{array}{l}\text { Standard } \\
\text { Deviation }\end{array}$ \\
\hline \multicolumn{6}{|c|}{ Services production } \\
\hline Sales & 257 & 36,403 & 6,569 & 798,279 & 118,663 \\
\hline Value added & 70 & 16,196 & 3,082 & 333,439 & 51,010 \\
\hline Capital & 2,189 & 201,392 & 32,373 & $4,745,895$ & 667,003 \\
\hline Employees & 24 & $3,179.99$ & 773 & 62,314 & 9,534 \\
\hline Wages & 40 & 10,203 & 1,891 & 226,977 & 33,383 \\
\hline \multicolumn{6}{|l|}{ Demand } \\
\hline Other firms & 916 & 7,225 & 4,338 & 42,477 & 8,809 \\
\hline Population & 57,313 & 399,814 & 269,699 & $1,838,882$ & 416,484 \\
\hline \multicolumn{6}{|c|}{ Competition } \\
\hline IT firms & 6 & 255 & 87 & 3,490 & 593 \\
\hline \multicolumn{6}{|l|}{ Investment } \\
\hline Investment & $-4,307$ & 1,068 & 168 & 23,349 & 3,594 \\
\hline
\end{tabular}


Table 4: Summary statistics of Swedish IT service grouped by size

\begin{tabular}{|c|c|c|c|c|c|}
\hline \multicolumn{6}{|c|}{ A. Small size IT service firms: 0-19 employees } \\
\hline Variable & Minimun & Mean & Median & Maximum & $\begin{array}{c}\text { Standard } \\
\text { Deviation }\end{array}$ \\
\hline \multicolumn{6}{|c|}{ Services production } \\
\hline Sales & 164 & 8,908 & 2,389 & 137,769 & 23,116 \\
\hline Value added & 70 & 3,721 & 1,102 & 52,299 & 9,324 \\
\hline Capital & 1,263 & 47,820 & 14,169 & 739,642 & 118,627 \\
\hline Employees & 17 & 799 & 273 & 10,861 & 1,855 \\
\hline Wages & 40 & 2,259 & 627 & 37,211 & 5,989 \\
\hline \multicolumn{6}{|c|}{ Competition } \\
\hline IT firms & 6 & 230 & 81 & 3,061 & 527 \\
\hline \multicolumn{6}{|l|}{ Investment } \\
\hline Investment & -234 & 249 & 75 & 4,771 & 660 \\
\hline \multicolumn{6}{|c|}{ B. Medium size IT service firms: 20-99 employees } \\
\hline \multicolumn{6}{|c|}{ Services production } \\
\hline Sales & 29 & 8,616 & 2,280 & 145,898 & 23,682 \\
\hline Value added & -55 & 3,782 & 1,102 & 61,821 & 9,837 \\
\hline Capital & 341 & 41,397 & 8,994 & 828,553 & 115,150 \\
\hline Employees & 20 & 846 & 260 & 13,128 & 2,102 \\
\hline Wages & 38 & 2,771 & 736 & 50,442 & 7,657 \\
\hline \multicolumn{6}{|c|}{ Competition } \\
\hline IT firms & 1 & 22 & 7 & 356 & 55 \\
\hline \multicolumn{6}{|l|}{ Investment } \\
\hline Investment & -183 & 245 & 44 & 5,753 & 703 \\
\hline \multicolumn{6}{|c|}{ C. Large size IT service firms: over 100 employees } \\
\hline \multicolumn{6}{|c|}{ Services production } \\
\hline Sales & 314 & 33,116 & 6,125 & 514,612 & 93,380 \\
\hline Value added & 217 & 15,211 & 3,329 & 224,736 & 41,269 \\
\hline Capital & 0 & 195,859 & 46,654 & $3,610,016$ & 579,167 \\
\hline Employees & 104 & 2,707 & 596 & 38,325 & 7,248 \\
\hline Wages & 184 & 9,107 & 1,746 & 139,325 & 25,648 \\
\hline \multicolumn{6}{|l|}{ Competition } \\
\hline IT firms & 1 & 7 & 2 & 90 & 17 \\
\hline \multicolumn{6}{|l|}{ Investment } \\
\hline Investment & $-4,393$ & 1,006 & 184 & 19,792 & 3,155 \\
\hline
\end{tabular}



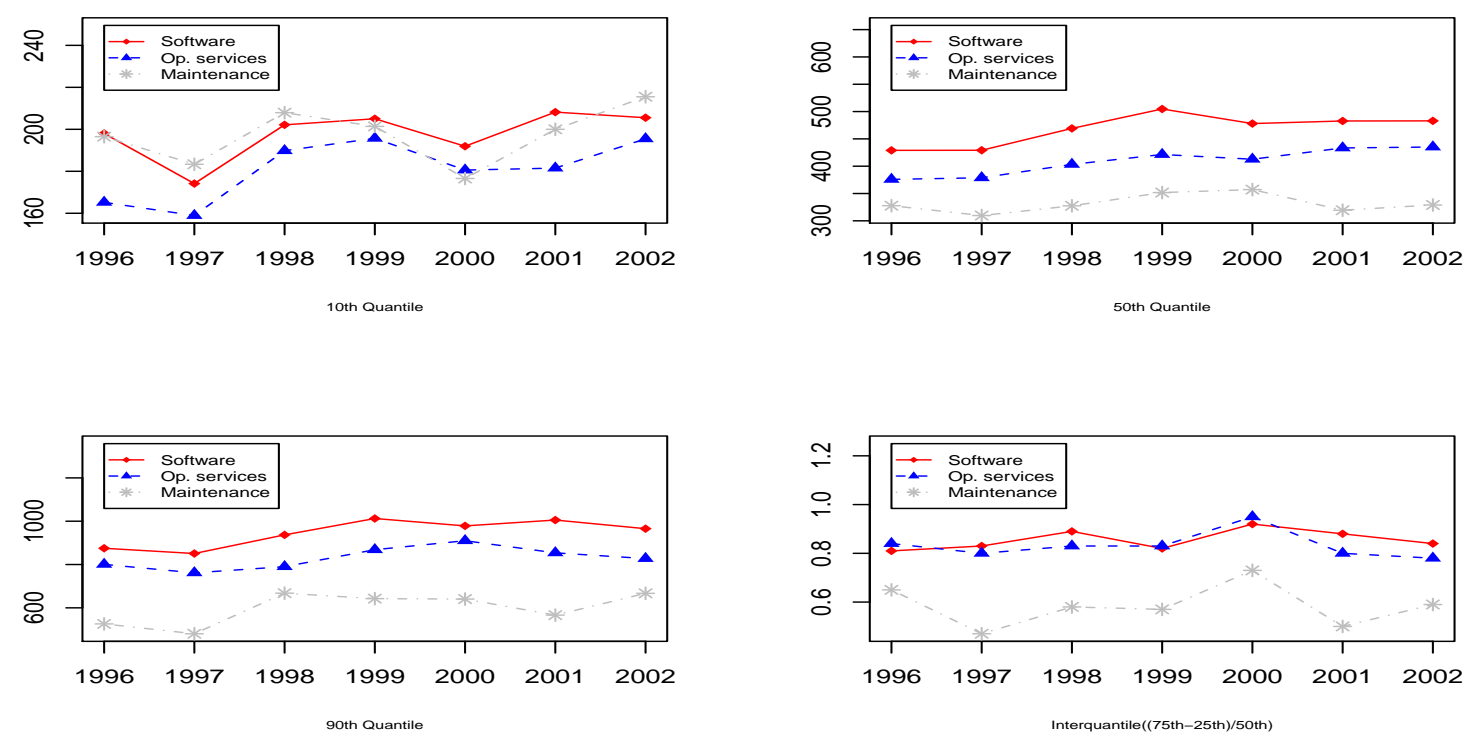

Figure 3: Evolution of the labor productivity percentiles and dispersion from 1996 to 2002.
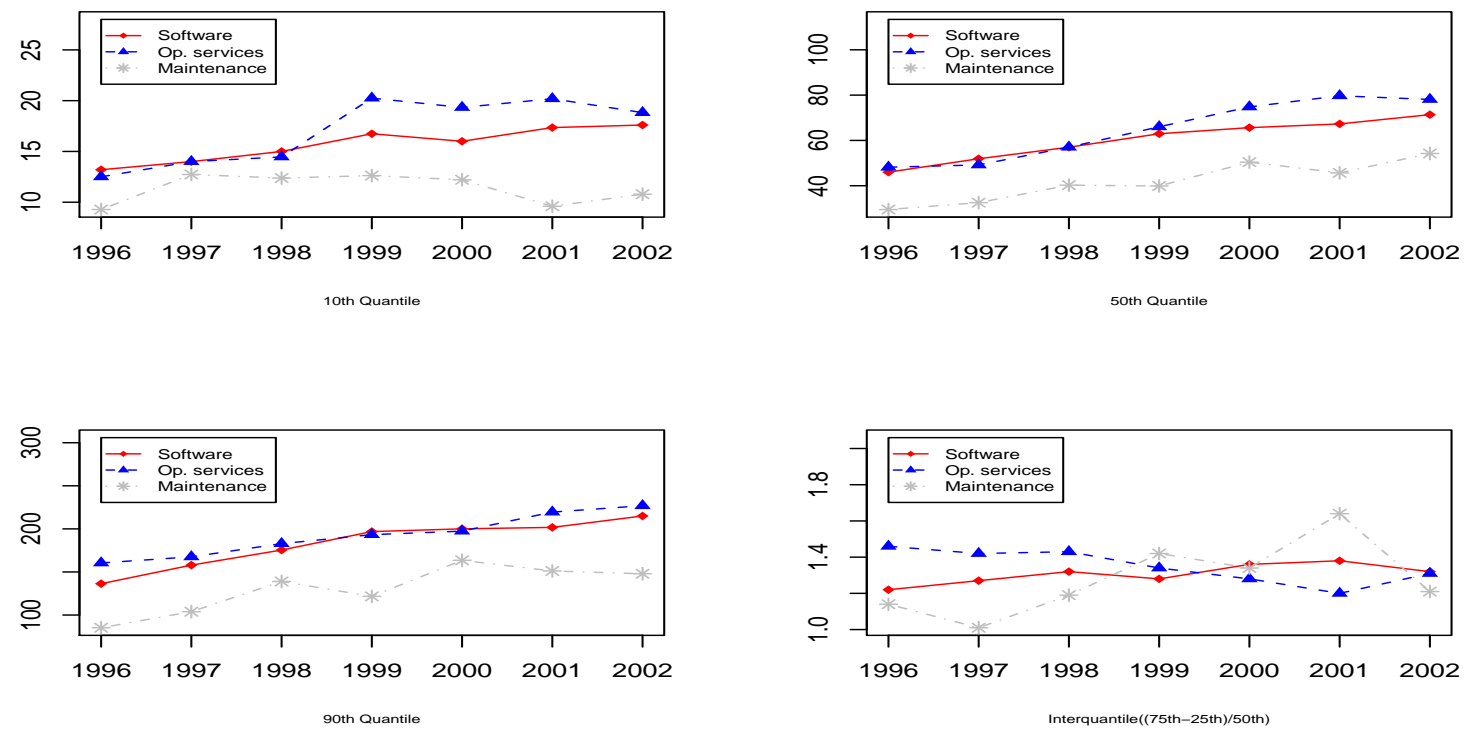

Figure 4: Evolution of the capital intensity percentiles and dispersion from 1996 to 2002. 
Table 5: Estimates of value-added generating function parameters in Swedish IT services

\begin{tabular}{|c|c|c|c|c|}
\hline & $\begin{array}{c}\text { OLS } \\
\text { software }\end{array}$ & $\begin{array}{c}\text { EOP } \\
\text { software }\end{array}$ & $\begin{array}{c}\text { OLS } \\
\text { Op. services and } \\
\text { maintenance }\end{array}$ & $\begin{array}{c}\text { EOP } \\
\text { Op. services and } \\
\text { maintenance }\end{array}$ \\
\hline Log No Emp. & $\begin{array}{l}1.017 \\
(0.006)\end{array}$ & $\begin{array}{l}0.680 \\
(0.0004)\end{array}$ & $\begin{array}{l}0.995 \\
(0.0163)\end{array}$ & $\begin{array}{l}0.789 \\
(0.031)\end{array}$ \\
\hline Log capital & $\begin{array}{l}0.118 \\
(0.004)\end{array}$ & $\begin{array}{l}0.374 \\
(0.004)\end{array}$ & $\begin{array}{l}0.169 \\
(0.010)\end{array}$ & $\begin{array}{l}0.208 \\
(0.003)\end{array}$ \\
\hline Market output & & $\begin{array}{l}0.217 \\
(0.004)\end{array}$ & & $\begin{array}{l}0.168 \\
(0.010)\end{array}$ \\
\hline $\begin{array}{l}\text { Scale } \\
\text { Demand } \\
\text { Mark-up } \\
\text { Sargan (p-value) }\end{array}$ & 1.135 & $\begin{array}{l}1.347 \\
-4.609 \\
1.277 \\
0.101\end{array}$ & 1.164 & $\begin{array}{l}1.196 \\
-5.96 \\
1.524 \\
0.125\end{array}$ \\
\hline No. obs. & 28,277 & 28,277 & 4,028 & 4,028 \\
\hline $\begin{array}{l}\text { NOTE: OLS is } \\
\text { parametric estim } \\
\text { GMM is used in } \\
\text { heteroscedasticity }\end{array}$ & OP estim & regression & $\begin{array}{l}\text { ag year dummies; } \\
\text { on 4, including sel } \\
\text { errors (in parenth }\end{array}$ & $\begin{array}{l}\text { is the semi- } \\
\text { Two-stage } \\
\text { re robust to }\end{array}$ \\
\hline
\end{tabular}
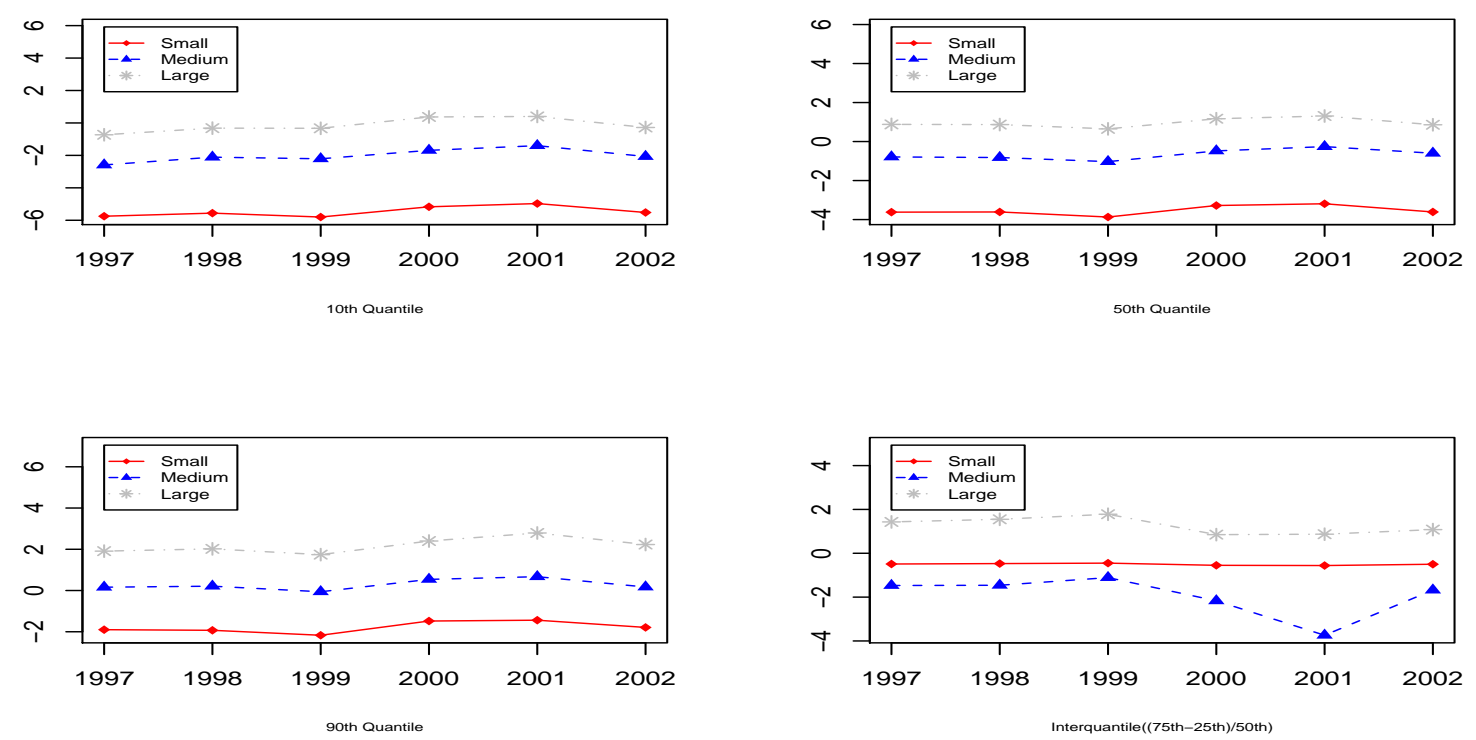

Figure 5: Evolution of productivity percentiles and dispersion for different size classes from 1996 to 2002. 
Table 6: Dynamic Olley-Pakes productivity decomposition with entry and exit

\begin{tabular}{cccccccc}
\hline \hline A. Software & & & \\
\hline
\end{tabular}
productivity. 
Table 7: Revenues function estimates

\begin{tabular}{|c|c|c|c|}
\hline \multicolumn{4}{|l|}{ A. Linear parametric specification } \\
\hline Variable & Software & $\begin{array}{l}\text { Operational } \\
\text { services }\end{array}$ & $\begin{array}{l}\text { Maintenance } \\
\text { and repair }\end{array}$ \\
\hline \multirow[t]{2}{*}{ Intercept } & 6.371 & 5.956 & 7.075 \\
\hline & $(0.102)$ & $(0.345)$ & $(0.686)$ \\
\hline \multirow[t]{2}{*}{ Own productivity } & 0.585 & 0.522 & 0.534 \\
\hline & $(0.004)$ & $(0.015)$ & $(0.028)$ \\
\hline \multirow[t]{2}{*}{ Own capital } & 0.367 & 0.292 & 0.326 \\
\hline & $(0.004)$ & $(0.013)$ & $(0.025)$ \\
\hline \multirow[t]{2}{*}{ Rivals' productivity } & $-6.63 \mathrm{E}-05$ & $-1.85 \mathrm{E}-04$ & $-3.45 \mathrm{E}-04$ \\
\hline & $(6.38 \mathrm{E}-06)$ & $(7.86 \mathrm{E}-05)$ & $(0.001)$ \\
\hline \multirow[t]{2}{*}{ Rivals' capital } & $-3.22 \mathrm{E}-08$ & $-1.05 \mathrm{E}-08$ & $-3.24 \mathrm{E}-06$ \\
\hline & $(4.57 \mathrm{E}-09)$ & $(6.13 \mathrm{E}-08)$ & $(3.79 \mathrm{E}-06)$ \\
\hline \multirow[t]{2}{*}{ Number of firms (other than IT) } & 0.119 & 0.327 & 0.222 \\
\hline & $(0.011)$ & $(0.039)$ & $(0.083)$ \\
\hline \multirow[t]{2}{*}{ Foreign owner } & 0.186 & 0.198 & 0.389 \\
\hline & $(0.032)$ & $(0.088)$ & $(0.276)$ \\
\hline \multirow[t]{2}{*}{ Medium size (20-99 employees) } & 0.199 & 0.042 & -0.054 \\
\hline & $(0.024)$ & $(0.073)$ & $(0.170)$ \\
\hline \multirow[t]{2}{*}{ Large size (over 100 employees) } & 0.458 & 0.304 & -0.098 \\
\hline & $(0.045)$ & $(0.139)$ & $(0.359)$ \\
\hline \multirow{2}{*}{ After 2000} & -0.202 & -0.194 & -0.335 \\
\hline & $(0.017)$ & $(0.052)$ & $(0.090)$ \\
\hline Adjusted $R^{2}$ & 0.821 & 0.814 & 0.808 \\
\hline Root of mean squares errors & 0.622 & 0.708 & 0.583 \\
\hline Absolute mean errors & 0.387 & 0.501 & 0.340 \\
\hline \multicolumn{4}{|c|}{ B. Linear non-parametric specification using cubic b-splines } \\
\hline \multicolumn{4}{|c|}{ Number of knots, $k_{n}=6$} \\
\hline \multicolumn{3}{|c|}{0.832} & 0.813 \\
\hline \multirow{2}{*}{$\begin{array}{l}\text { Root of mean squares errors } \\
\text { Absolute mean errors }\end{array}$} & 0.604 & & 0.562 \\
\hline & 0.365 & & 0.316 \\
\hline \multicolumn{4}{|c|}{ Number of knots, $k_{n}=9$} \\
\hline \multirow{3}{*}{$\begin{array}{l}\text { Adjusted } R^{2} \\
\text { Root of mean squares errors } \\
\text { Absolute mean errors }\end{array}$} & 0.833 & & 0.822 \\
\hline & 0.600 & & 0.524 \\
\hline & 0.360 & & 0.275 \\
\hline \multicolumn{4}{|c|}{ Number of knots, $k_{n}=14$} \\
\hline \multirow{3}{*}{$\begin{array}{l}\text { Adjusted } R^{2} \\
\text { Root of mean squares errors } \\
\text { Absolute mean errors }\end{array}$} & 0.834 & & 0.829 \\
\hline & 0.599 & & 0.496 \\
\hline & 0.359 & & 0.246 \\
\hline \multicolumn{4}{|c|}{$\begin{array}{l}\text { NOTE: The dependent variable is the log of revenues. The independent variables } \\
\text { are as follows: Own productivity measures the firm's productivity; own capital is } \\
\text { the firm's capital stock; rivals' productivity is the log of sum of rivals' productivity } \\
\text { at the county level; rivals' capital is the log of rivals' productivity at the county } \\
\text { level; Number of firms other than IT is the log of the number of non-IT firms at } \\
\text { the county level; population is the log of population at the county level; foreign } \\
\text { owner is a dummy variable indicating whether the firm has foreign ownership; } \\
\text { medium size (20-99 employees), large size (over } 100 \text { employees), and after } 2000 \\
\text { are dummy variables for the firm's size and the period following the } 2001 \text { dot-com } \\
\text { bust. For Panel A, the standard errors are in parentheses. }\end{array}$} \\
\hline
\end{tabular}


Table 8: Entry and exit policy functions estimation results

\begin{tabular}{|c|c|c|c|}
\hline \multicolumn{4}{|l|}{ A. Exit policies } \\
\hline Variable & Software & $\begin{array}{c}\text { Operational } \\
\text { services }\end{array}$ & $\begin{array}{l}\text { Maintenance } \\
\text { and repair }\end{array}$ \\
\hline \multirow[t]{2}{*}{ Intercept } & 14.292 & -0.744 & -0.431 \\
\hline & $(0.479)$ & $(0.948)$ & $(2.32)$ \\
\hline \multirow[t]{2}{*}{ Own productivity } & -0.321 & -0.389 & -0.285 \\
\hline & $(0.014)$ & $(0.036)$ & $(0.087)$ \\
\hline \multirow[t]{2}{*}{ Own capital } & 0.027 & 0.084 & 0.021 \\
\hline & $(0.012)$ & $(0.032)$ & $(0.086)$ \\
\hline \multirow[t]{2}{*}{ Rivals' productivity } & -0.771 & 0.022 & -0.350 \\
\hline & $(0.022)$ & $(0.042)$ & $(0.179)$ \\
\hline \multirow[t]{2}{*}{ Rivals' capital } & -0.646 & 0.093 & -0.204 \\
\hline & $(0.035)$ & $(0.043)$ & $(0.116)$ \\
\hline \multirow{2}{*}{ Number of firms (other than IT) } & -0.208 & -0.496 & -0.033 \\
\hline & $(0.035$ & $(0.120)$ & $(0.268)$ \\
\hline \multirow[t]{2}{*}{ Foreign owner } & 0.628 & 0.730 & 1.122 \\
\hline & $(0.102)$ & $(0.226)$ & $(0.635)$ \\
\hline \multirow[t]{2}{*}{ Medium size (20-99 employees) } & 0.015 & 0.795 & 0.687 \\
\hline & $(0.088)$ & $(0.200)$ & $(0.601)$ \\
\hline \multirow[t]{2}{*}{ Large size (over 100 employees) } & 1.484 & 0.548 & 0.614 \\
\hline & $(0.149)$ & $(0.415)$ & $(1.004)$ \\
\hline \multirow[t]{2}{*}{ After 2000} & 1.978 & 2.079 & 2.603 \\
\hline & $(0.035)$ & $(0.093)$ & $(0.247)$ \\
\hline Log-likelihood & -11851.188 & -1635.361 & -270.744 \\
\hline The likelihood ratio index & 0.389 & 0.289 & 0.390 \\
\hline \multicolumn{4}{|l|}{ B. Entry policies } \\
\hline \multirow[t]{2}{*}{ Intercept } & -1.051 & -3.144 & -4.822 \\
\hline & $(0.353)$ & $(0.860)$ & $(1.931)$ \\
\hline \multirow[t]{2}{*}{ Rivals' productivity } & 0.068 & 0.184 & 0.434 \\
\hline & $(0.015)$ & $(0.036)$ & $(0.150)$ \\
\hline \multirow[t]{2}{*}{ Rivals' capital } & -0.192 & -0.016 & 0.100 \\
\hline & $(0.028)$ & $(0.039)$ & $(0.110)$ \\
\hline \multirow[t]{2}{*}{ Number of firms (other than IT) } & 0.265 & 0.177 & 0.134 \\
\hline & $(0.028)$ & $(0.116)$ & $(0.232)$ \\
\hline \multirow[t]{2}{*}{ Foreign owner } & -0.581 & -0.468 & 0.334 \\
\hline & $(0.115)$ & $(0.287)$ & $(0.744)$ \\
\hline \multirow[t]{2}{*}{ Medium size (20-99 employees) } & -0.867 & -0.902 & -0.784 \\
\hline & $(0.064)$ & $(0.168)$ & $(0.631)$ \\
\hline \multirow[t]{2}{*}{ Large size (over 100 employees) } & -1.307 & -1.665 & -0.234 \\
\hline & $(0.165)$ & $(0.478)$ & $(1.016)$ \\
\hline \multirow[t]{2}{*}{ After 2000} & -0.760 & -1.240 & -1.416 \\
\hline & $(0.034)$ & $(0.107)$ & $(0.282)$ \\
\hline Log-likelihood & -15849.964 & -1852.225 & -330.732 \\
\hline The likelihood ratio index & 0.184 & 0.194 & 0.255 \\
\hline \multicolumn{4}{|c|}{$\begin{array}{l}\text { NOTE: The estimations are done using logit estimator. The independent } \\
\text { variables are as follows: Own productivity measures the firm's productivity; } \\
\text { own capital is the firm's capital stock; rivals' productivity is the log of sum } \\
\text { of rivals' productivity at the county level; rivals' capital is the log of rivals' } \\
\text { productivity at the county level; Number of firms other than IT is the log } \\
\text { of the number of non-IT firms at the county level; population is the log of } \\
\text { population at the county level; foreign owner is a dummy variable indicating } \\
\text { whether the firm has foreign ownership; medium size (20-99 employees), large } \\
\text { size (over } 100 \text { employees), and after } 2000 \text { are dummy variables for the firm's } \\
\text { size and the period following the } 2001 \text { dot-com bust. The standard errors are } \\
\text { in parentheses. }\end{array}$} \\
\hline
\end{tabular}


Table 9: Investment policy functions estimation results

\begin{tabular}{|c|c|c|c|}
\hline \multicolumn{4}{|l|}{ A. Investment policies for IT services } \\
\hline Variable & Software & $\begin{array}{c}\text { Operational } \\
\text { services }\end{array}$ & $\begin{array}{l}\text { Maintenance } \\
\text { and repair }\end{array}$ \\
\hline \multirow[t]{2}{*}{ Intercept } & -1.565 & -3.635 & -0.778 \\
\hline & $(3.682)$ & $(5.385)$ & $(0.543)$ \\
\hline \multirow[t]{2}{*}{ Own productivity } & 0.078 & 0.201 & -0.003 \\
\hline & $(0.032)$ & $(0.179)$ & $(0.019)$ \\
\hline \multirow[t]{2}{*}{ Own capital } & 0.474 & 0.947 & 0.105 \\
\hline & $(0.027)$ & $(0.165)$ & $(0.017)$ \\
\hline \multirow[t]{2}{*}{ Rivals' productivity } & -0.067 & 1.898 & 0.251 \\
\hline & $(0.268)$ & $(4.155)$ & $(0.446)$ \\
\hline \multirow[t]{2}{*}{ Rivals' capital } & -1.732 & -4.728 & -0.318 \\
\hline & $(4.573)$ & $(6.855)$ & $(0.175)$ \\
\hline \multirow[t]{2}{*}{ Number of firms (other than IT) } & 0.108 & 0.245 & 0.041 \\
\hline & $(0.057)$ & $(0.425)$ & $(0.039)$ \\
\hline \multirow[t]{2}{*}{ Foreign owner } & 0.632 & 1.940 & 0.631 \\
\hline & $(0.212)$ & $(1.059)$ & $(0.192)$ \\
\hline \multirow[t]{2}{*}{ Medium size (20-99 employees) } & -0.551 & -2.328 & 0.373 \\
\hline & $(0.157)$ & $(0.881)$ & $(0.118)$ \\
\hline \multirow{2}{*}{ Large size (over 100 employees) } & 9.192 & 27.088 & 2.120 \\
\hline & $(0.295)$ & $(1.672)$ & $(0.253)$ \\
\hline \multirow[t]{2}{*}{ After 2000} & -0.188 & -0.466 & -0.127 \\
\hline & $(0.089)$ & $(0.553)$ & $(0.061)$ \\
\hline Adjusted $R^{2}$ & 0.174 & 0.367 & 0.583 \\
\hline Root of mean squares errors & 4.085 & 8.501 & 0.405 \\
\hline Absolute mean errors & 16.688 & 72.280 & 0.165 \\
\hline Correlation (observed,predicted) & 0.418 & 0.609 & 0.770 \\
\hline \multicolumn{4}{|c|}{ B. Linear non-parametric specification using cubic b-splines } \\
\hline \multicolumn{4}{|c|}{ Number of knots, $k_{n}=6$} \\
\hline Adjusted $R^{2}$ & 0.729 & 0.743 & 0.877 \\
\hline Root of mean squares errors & 2.335 & 5.382 & 0.213 \\
\hline Absolute mean errors & 5.451 & 28.966 & 0.045 \\
\hline Correlation (observed,predicted) & 0.854 & 0.883 & 0.942 \\
\hline \multicolumn{4}{|c|}{ Number of knots, $k_{n}=9$} \\
\hline Adjusted $R^{2}$ & 0.836 & 0.767 & 0.945 \\
\hline Root of mean squares errors & 1.818 & 5.075 & 0.136 \\
\hline Absolute mean errors & 3.305 & 25.763 & 0.018 \\
\hline Correlation (observed,predicted) & 0.915 & 0.887 & 0.976 \\
\hline \multicolumn{4}{|c|}{ Number of knots, $k_{n}=14$} \\
\hline Adjusted $R^{2}$ & 0.869 & 0.854 & 0.950 \\
\hline Root of mean squares errors & 1.618 & 3.997 & 0.125 \\
\hline Absolute mean errors & 2.619 & 15.982 & 0.015 \\
\hline Correlation (observed,predicted) & 0.933 & 0.930 & 0.980 \\
\hline \multicolumn{4}{|c|}{$\begin{array}{l}\text { NOTE: The dependent variable is the investment expenditure in ten thousand } \\
\text { Swedish krona. The independent variables are as follows: Own productivity, } \\
\text { measures the firm's productivity; own capital is the firm's capital stock; rivals, } \\
\text { productivity is the log of sum of rivals' productivity at the county level; rivals, } \\
\text { capital is the log of rivals' productivity at the county level; Number of firms } \\
\text { other than IT is the log of the number of non-IT firms at the county level; } \\
\text { population is the log of population at the county level; foreign owner is a } \\
\text { dummy variable indicating whether the firm has foreign ownership; medium } \\
\text { size (20-99 employees), large size (over } 100 \text { employees), and after } 2000 \text { are } \\
\text { dummy variables for the firm's size and the period following the } 2001 \text { dot-com } \\
\text { bust. For Panel A, the standard errors are in parentheses. }\end{array}$} \\
\hline
\end{tabular}


Table 10: Labor policy functions estimation results

\begin{tabular}{|c|c|c|c|}
\hline \multicolumn{4}{|l|}{ A. Labor policies for IT services } \\
\hline Variable & Software & $\begin{array}{c}\text { Operational } \\
\text { services }\end{array}$ & $\begin{array}{l}\text { Maintenance } \\
\text { and repair }\end{array}$ \\
\hline \multirow[t]{2}{*}{ Intercept } & 1.012 & 1.603 & 1.620 \\
\hline & $(0.423)$ & $(0.619)$ & $(0.824)$ \\
\hline \multirow[t]{2}{*}{ Own productivity } & 0.522 & 0.482 & 0.485 \\
\hline & $(0.002)$ & $(0.006)$ & $(0.010)$ \\
\hline \multirow[t]{2}{*}{ Own capital } & 0.267 & 0.199 & 0.151 \\
\hline & $(0.002)$ & $(0.006)$ & $(0.016)$ \\
\hline \multirow[t]{2}{*}{ Rivals' productivity } & -1.261 & -2.542 & -1.069 \\
\hline & $(0.174)$ & $(0.387)$ & $(0.568)$ \\
\hline \multirow[t]{2}{*}{ Rivals' capital } & -1.224 & -0.339 & -0.302 \\
\hline & $(0.725)$ & $(0.680)$ & $(0.151)$ \\
\hline \multirow[t]{2}{*}{ Number of firms (other than IT) } & 0.017 & 0.327 & 0.500 \\
\hline & $(0.041)$ & $(0.105)$ & $(0.158)$ \\
\hline \multirow[t]{2}{*}{ Population } & 0.122 & -0.025 & -0.177 \\
\hline & $(0.045)$ & $(0.116)$ & $(0.173)$ \\
\hline \multirow{2}{*}{ Foreign owner } & 0.098 & 0.078 & 0.372 \\
\hline & $(0.018)$ & $(0.041)$ & $(0.092)$ \\
\hline \multirow{2}{*}{ After 2000} & -0.278 & -0.243 & -0.219 \\
\hline & $(0.009)$ & $(0.022)$ & $(0.036)$ \\
\hline Adjusted $R^{2}$ & 0.899 & 0.929 & 0.939 \\
\hline Root of mean squares errors & 0.351 & 0.329 & 0.245 \\
\hline Absolute mean errors & 0.123 & 0.108 & 0.060 \\
\hline Correlation (observed,predicted) & 0.949 & 0.964 & 0.970 \\
\hline \multicolumn{4}{|c|}{ B. Linear non-parametric specification using cubic b-splines } \\
\hline \multicolumn{4}{|c|}{ Number of knots, $k_{n}=6$} \\
\hline Adjusted $R^{2}$ & 0.943 & -1.272 & 0.960 \\
\hline Root of mean squares errors & 0.069 & 1.865 & 0.193 \\
\hline Absolute mean errors & 0.263 & 3.480 & 0.037 \\
\hline Correlation (observed,predicted) & 0.971 & 0.584 & 0.981 \\
\hline \multicolumn{4}{|c|}{ Number of knots, $k_{n}=9$} \\
\hline Adjusted $R^{2}$ & 0.945 & -8.892 & 0.963 \\
\hline Root of mean squares errors & 0.067 & 3.858 & 0.178 \\
\hline Absolute mean errors & 0.259 & 14.888 & 0.031 \\
\hline Correlation (observed,predicted) & 0.972 & 0.507 & 0.984 \\
\hline \multicolumn{4}{|c|}{ Number of knots, $k_{n}=14$} \\
\hline Adjusted $R^{2}$ & 0.946 & -2.010 & 0.964 \\
\hline Root of mean squares errors & 0.065 & 2.112 & 0.169 \\
\hline Absolute mean errors & 0.256 & 4.461 & 0.028 \\
\hline Correlation (observed,predicted) & 0.973 & 0.475 & 0.985 \\
\hline
\end{tabular}

NOTE: The dependent variable is the log of number of employees. The independent variables are as follows: Own productivity measures the firm's productivity; own capital is the firm's capital stock; rivals' productivity is the log of sum of rivals' productivity at the county level; rivals' capital is the log of rivals' productivity at the county level; Number of firms other than IT is the $\log$ of the number of non-IT firms at the county level; population is the log of population at the county level; foreign owner is a dummy variable indicating whether the firm has foreign ownership; medium size (20-99 employees), large size (over 100 employees), and after 2000 are dummy variables for the firm's size and the period following the 2001 IT bubble burst. For Panel A, the standard errors are in parentheses. 
Table 11: Cost estimates by sub-sector before and after the 2001 dot-com bust

\begin{tabular}{|c|c|c|c|c|c|c|}
\hline \multirow[t]{2}{*}{ Variable } & \multicolumn{2}{|c|}{ Software } & \multicolumn{2}{|c|}{$\begin{array}{c}\text { Operational } \\
\text { services }\end{array}$} & \multicolumn{2}{|c|}{$\begin{array}{c}\text { Maintenance } \\
\text { and repair }\end{array}$} \\
\hline & Before & After & Before & After & Before & After \\
\hline \multicolumn{7}{|l|}{ A: Investment cost } \\
\hline Setup investment & 170.61 & 323.68 & 667.13 & 645.98 & 193.01 & 148.23 \\
\hline Std. & $(9.60)$ & $(7.63)$ & $(5.81)$ & $(9.51)$ & $(8.59)$ & $(5.27)$ \\
\hline Variable investment & 6.26 & 5.36 & 10.02 & 13.80 & 34.39 & 14.07 \\
\hline Std. & $(0.16)$ & $(0.60)$ & $(0.33)$ & $(0.70)$ & $(4.57)$ & $(9.36)$ \\
\hline Variable investment squared & $6.76 \mathrm{e}-6$ & $295 \mathrm{e}-5$ & $4.09 \mathrm{e}-5$ & $8.60 \mathrm{e}-5$ & 0.003 & 0.06 \\
\hline Std. & $(8.03 \mathrm{e}-7)$ & $(4.32 \mathrm{e}-6)$ & $(2.10 \mathrm{e}-6)$ & $(5.37 \mathrm{e}-6)$ & $(0.0008)$ & $(0.04)$ \\
\hline \multicolumn{7}{|c|}{ B: Implied distributions of investment costs } \\
\hline Investment - mean & $4,293.81$ & $4,673.79$ & $3,015.53$ & $3,491.63$ & $1,043.34$ & 787,17 \\
\hline Investment - std. & $2,992.91$ & 44.75 & 241.43 & 453.68 & 50.69 & 75.27 \\
\hline \multicolumn{7}{|l|}{ C: Labor adjustment cost } \\
\hline Setup positive adjustemnt & 141.89 & 666.67 & 413.50 & 89.63 & 400.47 & 404.28 \\
\hline Std. & $(78.92)$ & $(347.88)$ & $(151.26)$ & $(34.89)$ & $(60.20)$ & $(87.47)$ \\
\hline Variable positive adjustment & 322.58 & 271.27 & 379.26 & 432.708 & 294.36 & 245.14 \\
\hline Std. & $(2.81)$ & $(2.17)$ & $(2.06)$ & $(4.34)$ & $(9.76)$ & $(2.20)$ \\
\hline Setup negative adjustment & 167.12 & 366.72 & 562.01 & 210.55 & 337.74 & \\
\hline Std. & $(67.37)$ & $(89.02)$ & $(87.50)$ & $(93.33)$ & $(99.74)$ & \\
\hline Variable negative adjustment & 285.14 & 285.82 & 324.05 & 279.41 & 262.132 & \\
\hline Std. & $(1.47)$ & $(4.57)$ & $(3.959)$ & $(26.38)$ & $(2.01)$ & \\
\hline \multicolumn{7}{|c|}{ D: Implied distributions of labor adjustment costs } \\
\hline Positive adjustment - mean & $2,587.32$ & $2,890.39$ & $2,000.37$ & $1,515.04$ & $2,534.41$ & 2,089 \\
\hline Positive adjustment - std. & $1,039.67$ & $1,943.26$ & 171.25 & 671.25 & 475.75 & 319.42 \\
\hline Negative adjustment - mean & 1,262 & $1,429.50$ & $1,650.87$ & 927.97 & $1,003.73$ & \\
\hline Negative adjustment - std. & 478.26 & 631,68 & 287.41 & 150.04 & 66.98 & \\
\hline \multicolumn{7}{|l|}{ E: Exit costs } \\
\hline Scrap (sell-of values) & 170.01 & 175.01 & 230.00 & 255.15 & 260.11 & 248.04 \\
\hline Std. & $(61.02)$ & $(50.29)$ & $(27.24)$ & $(23.45)$ & $(40.57)$ & $(34.78)$ \\
\hline \multicolumn{7}{|l|}{ F: Entry costs } \\
\hline Sunk cost & 18.69 & 19.92 & 120.61 & 120.33 & 135.96 & 117.14 \\
\hline Std. & $(4.08)$ & $(4.66)$ & $(34.63)$ & $(34.53)$ & $(146.97)$ & $(104.30)$ \\
\hline
\end{tabular}

NOTE: The estimates are obtained using 2,000 simulations with 100 years each, where the initial states are held constant across simulations. Standard errors in parentheses. 
Appendix A: Data. This section describes the variables in the data. Value added is total shipments, adjusted for changes in inventories, minus the cost of materials. Real value added is constructed by deflating value added by a fivedigit industry output deflater. The deflectors are taken from Statistics Sweden. The labor variable is the total number of employees. The total wages come from RAMS. I deflated sales, wages, and investment by the consumer price index (CPI) from IMF-CDROM 2005. The capital measure is constructed using a perpetual inventory method, $k_{t+1}=(1-\delta) k_{t}+i_{t}$. Since the capital data distinguish between buildings and equipment, all calculations of the capital stock are done separately for buildings and equipment. As suggested by Hulten and Wykoff (1981), equipment is depreciated at a rate of 0.1179 . In the empirical part, the paper only uses machinery and equipment in the capital stock measure.

Appendix B: Productivity estimation. Considering the high turnover in the IT industry, it is important to control for selection. Olley and Pakes' (1996) approach to control for selection is to substitute the predicted survival probability $\mathscr{P}_{t-1}$ into $g(\cdot)$. Thus, the final value-added generating function to be estimated is

$$
\begin{aligned}
y_{j t}= & \left(1+\frac{1}{\eta}\right)\left[\beta_{0}+\beta_{l} l_{j t}+\beta_{k} k_{j t}\right]+-\frac{1}{\eta} q_{m t}-\frac{1}{\eta} z_{m t}^{\prime} \beta_{z}+g\left(\mathscr{P}_{t-1}, \omega_{j t-1}\right) \\
& +\left(1+\frac{1}{\eta}\right) \xi_{j t}-\frac{1}{\eta} u_{j t}^{d}+\left(1+\frac{1}{\eta}\right) u_{j t}^{p},
\end{aligned}
$$

where $\omega_{j t-1}$ comes from (8). ${ }^{45}$

The value-added generating function (23) is estimated using the sieve minimum distance (SMD) procedure proposed by Newey and Powell (2003) and Ai and Chen (2003) for independent and identically distributed (i.i.d) data. The goal is to obtain an estimable expression for the unknown parameters $\boldsymbol{\beta}$ and $g_{K_{T}}$ where

\footnotetext{
${ }^{45}$ The condition for identification is that the variables in the parametric part of the model are not perfectly predictable (in the least square sense) by the variables in the non-parametric part (Robinson, 1988). Hence, there cannot be a functional relationship between the variables in the parametric and non-parametric part (Newey et al., 1999). Including additional variables that affect productivity guarantees the identification.
} 
$K_{T}$ indicates all parameters in $g(\cdot)$. To approximate $g(\cdot)$, a third order polynomial in $\omega_{t-1}$ is used. ${ }^{46} \mathrm{~A}$ tensor product polynomial series of $\left\{1, l_{t-1}, k_{t-1}, p_{I t-1}, w_{m t-1}\right.$, $\left.\mathbf{z}_{m t-1}\right\}$ are used as instruments. Using the GMM implementation, the parameter values $\left(\boldsymbol{\beta}, g_{K_{T}}\right)$ are jointly estimated. The Nelder-Mead numerical optimization method is used to minimize the GMM objective function.

Appendix C: B-Splines. We consider a cubic spline, $f(x), x \in[a, b]$, with $q$ interior knots, $\xi_{i}, i=1, \cdots, q$, that can be written as a sum of piecewise polynomials of order 4 (degree 3 ) on the any interval $\left[\xi_{i-1}, \xi_{i}\right]$,

$$
f(x)=\sum_{m=0}^{3} \delta_{m i} x^{m}, \quad x \in\left[\xi_{i-1}, \xi_{i}\right), \quad i=1, \cdots, q, \quad \text { or } \quad x \in\left[\xi_{q}, \xi_{q+1}\right], i=q+1 .
$$

The function $f(x)$ is assumed to be twice continuously differentiable. Collinearity is a potential problem when using cubic spline in regressions. For this reason, the b-splines are preferred because of their numerical properties. For b-splines, the basis is derived recursively. ${ }^{47}$ To do this, additional knots, such as $\xi_{-3}=\xi_{-2}=$ $\xi_{-1}=a$ and $\xi_{q+2}=\xi_{r+3}=\xi_{r+4}=b$, have to be added. The basis for b-splines, $\left\{B_{i, 4}\right\}_{i=-3}^{q}$ is given by

$$
B_{i, n}=\frac{x-\xi_{i}}{\xi_{i+n-1}-\xi_{i}} B_{i, n-1}(x)+\frac{\xi_{i+n}-x}{\xi_{i+n}-\xi_{i+1}} B_{i+1, n-1}(x), \quad \text { if } \quad n=2,3,4,
$$

where $B_{i, 1}(x)$ is equal to 1 if $x \in\left[\xi_{i}, \xi_{i+1}\right)$ and 0 otherwise. Having the basis, the cubic b-spline is given by

$$
b s(x)=\sum_{i=1}^{q+4} \alpha_{i} B_{i-4,4}(x),
$$

\footnotetext{
${ }^{46}$ For robustness, the expand $g(\cdot)$ using a 4 th order polynomial was also used. Yet, the results were similar.

${ }^{47}$ Schumaker (1981) provides a detailed overview on spline theory. de Boor (1978) and Eubank (1988) provide detailed information on b-splines.
} 
where $\alpha_{i}, i=1, \cdots, q+4$ is the set of coefficients. 